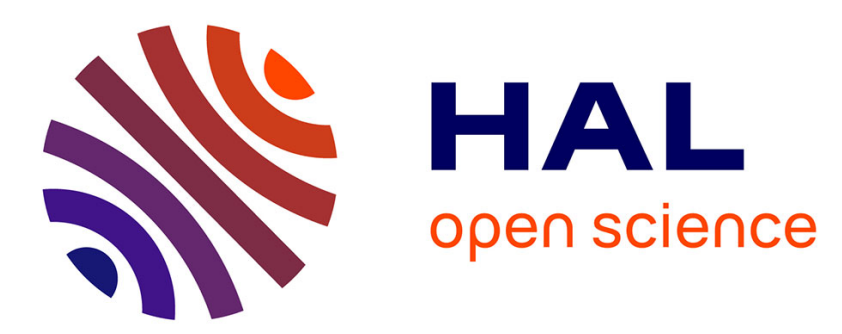

\title{
Output contingent securities and efficient investment by firms
}

\author{
Luis H. B. Braido, Victor Filipe Martins da Rocha
}

\section{To cite this version:}

Luis H. B. Braido, Victor Filipe Martins da Rocha. Output contingent securities and efficient investment by firms. International Economic Review, 2018, 59 (2), pp.989-1012. 10.1111/iere.12294 . hal-01097363v4

\section{HAL Id: hal-01097363 \\ https://hal.science/hal-01097363v4}

Submitted on 13 Oct 2017

HAL is a multi-disciplinary open access archive for the deposit and dissemination of scientific research documents, whether they are published or not. The documents may come from teaching and research institutions in France or abroad, or from public or private research centers.
L'archive ouverte pluridisciplinaire HAL, est destinée au dépôt et à la diffusion de documents scientifiques de niveau recherche, publiés ou non, émanant des établissements d'enseignement et de recherche français ou étrangers, des laboratoires publics ou privés. 


\title{
Output contingent securities and efficient investment by firms*
}

\author{
Luis H. B. Braido And V. Filipe Martins-DA-RochA ${ }^{1}$ \\ Getulio Vargas Foundation-FGV/EPGE, Brazil; Sao Paulo School of \\ Economics-FGV, Brazil and Ceremade, CNRS, Université Paris-Dauphine, \\ PSL Research University, France
}

\begin{abstract}
We analyze competitive economies with risky investments. Unlike the classic Arrow-Debreu framing, firms and agents cannot contract upon the exogenous states underlying production risks. They can trade equities and any security written on the endogenous aggregate output. This financial structure is rich enough to promote efficient risk sharing among consumers. However, markets are incomplete from the production perspective, and the absence of prices for each primitive state of nature raises the question about the objective of firms. We show that output-contingent asset prices convey sufficient information to compute the competitive shareholder value that leads to efficient investment by firms.

Running Head: Output contingent securities

Keywords: CAPM, competitive equilibrium, production, investment, efficiency, endogenous risk, incomplete markets.

JEL Classification: D51, D53, G11.
\end{abstract}

\section{Introduction}

Following the work by Léon Walras in the 19th century, the general equilibrium literature focused on understanding how anonymous markets coordinate the

\footnotetext{
${ }^{1}$ This paper has benefited from insightful interactions with Piero Gottardi, Michael Magill, Herakles Polemarchakis, Martine Quinzii, and Paolo Siconolfi. We are also thankful to comments from Yves Balasko, Alessandro Citanna, Jan Eeckhout, John Geanakoplos, Jayant Ganguli, Christian Ghiglino, Zhiguo He, Felix Kubler, Karl Shell, Stephen Spear, Jan Werner, and seminar participants at the Cowles Foundation, Exeter Business School, Sao Paulo School of Economics, Université Paris-Dauphine, University of York, Econometric Society Meetings at Malaga and Evanston, and NSF/NBER/CEME Conference at Indiana University. Financial support from CNPq is gratefully acknowledged. Please address correspondence to: Luis Braido, Fundação Getulio Vargas, Escola Brasileira de Economia e Finanças, Praia de Botafogo 190, Rio de Janeiro, RJ 22250-900, Brazil. Phone: +55 213799 5868. Fax: +55 212553 8821. E-mail: Luis.Braido@fgv.br

*Manuscript received August 2015; revised November 2016.
} 
production and consumption of goods in competitive economies. In this setting, firms' productive decisions and agents' consumption choices are taken independently, and market prices are the only instruments available to coordinate different wishes. Hayek (1945) supported the view that competitive prices have the capacity of aggregating the necessary social knowledge to induce efficiency of self-interested decisions. This idea was rigorously formulated and independently proven by Kenneth J. Arrow, Gerard Debreu, and Lionel W. McKenzie during the 1950's. They listed conditions for existence of a competitive equilibrium and proved that, in the absence of externalities and other market frictions, competitive markets lead profit-maximizing firms and utility-maximizing agents to achieve a Pareto optimal allocation of resources. The information embedded in market prices is sufficient to promote efficient social coordination across decision makers.

Arrow (1953) and Debreu (1959) extended the general equilibrium analysis to economies in which random states of nature affect production. They showed that the classic results carry over to environments with uncertainty whenever decision makers are able to trade a complete set of contingent claims - each of them promising to deliver goods in the future contingent to the verification of a given state of nature. However, the description and verification of primitive states are not simple matters, and most securities traded in modern financial markets are contingent on observed outcomes instead of primitive states of nature.

We analyze competitive financial economies in which firms make risky investments and consumers trade firms' equities and securities written on firms' endogenous production. Since our goal is to analyze efficiency of firms' investment decisions, we assume that financial markets allow consumers to insure each other against idiosyncratic risks and make consumption plans contingent on aggregate output. It is well-known that this market structure is sufficient to implement Pareto optimal allocations in exchange economies. We analyze the conditions under which this also holds for production economies.

This topic was introduced by Magill and Quinzii (2009, 2010). These papers develop a concept for computing the shareholder value of large corporations and show that Pareto efficiency does not always follow from shareholder value maximization. We argue that profit maximization can still be socially justified as a decision criterion if firms are assumed to behave as perfect competitors. Although output-contingent prices do not a priori convey all the requisite information to coordinate consumption and investment decisions, we show that this issue can be overcome if firms and agents anticipate out-of-equilibrium scenarios in a competitive fashion. In the standard Arrow-Debreu approach, all relevant information for an efficient investment decision is embedded in the state-contingent prices. In the output-contingent framing, however, financial markets do not necessarily distinguish across states of nature that lead to the same equilibrium aggregate output. This distinction is still relevant for firms' decisions. We accommodate the competitive price-taking paradigm by assuming that firms and agents combine market prices with competitive beliefs 
about how alternative investment plans would affect the conditional expectation of each firm's output given the economy's aggregate production ${ }^{2}$

We start by stressing the main insights in a simple example with only two possible production levels. We describe the general model and formally define the competitive financial equilibrium in Section 3. Agents in this economy can only trade securities written on endogenous production levels. This financial structure is incomplete with respect to the underlying primitive states of nature but allows consumers to sell their endowment risks and make consumption plans that are contingent on the equilibrium aggregate output. In Section 4, we introduce our view on how competitive firms should compute the net present value of out-of-equilibrium investment plans. We argue that the financial equilibrium in which firms maximize our definition of market value is the counterpart of the Arrow-Debreu concept. In particular, we show that the associated consumption and investment allocation is Pareto optimal. In Section 5, we discuss some important topics related to our contribution. We stress how the results depend on our assumptions and then discuss existence of a competitive equilibrium for different specifications of the productive technology. We also use this section to compare our competitive notion of shareholder value to the alternative concepts in which firms exert market power by internalizing parts of the impact of their investment decisions.

Next, in Section 6, we describe our main contribution using the CAPM framework. Financial markets trade only stocks and a risk-free bond. Since agents hold mean-variance preferences, efficient risk sharing among consumers is achieved under this incomplete financial structure. Like before, this guarantees that firms can compute the competitive market value for different out-of-equilibrium investments and that profit-maximization generates Pareto efficiency. This section is self-contained and is particularly interesting for the reader who is familiar with the finance literature and is not concerned with general equilibrium details. Concluding remarks appear in Section 7. Appendix $\mathrm{A}$ is reserved for technical arguments.

\section{An illustration}

We borrow from Magill and Quinzii (2009) the following simple example with two periods $t \in\{0,1\}$, one good, one firm, and one agent. At date 0 , the firm

\footnotetext{
${ }^{2}$ This competitiveness assumption on firms is consistent with the literature on the objective of corporations under incomplete markets - see for instance Drèze (1974), Ekern and Wilson (1974), Leland (1974), Ekern (1975), Hart (1979), Grossman and Hart (1979), Makowski (1983), and Bisin, Gottardi and Ruta (2014). Our markets are also incomplete with respect to exogenous uncertainty, and the spanning condition of Ekern and Wilson (1974) does not hold here (in the sense that investments do affect the individual ability to transfer wealth across primitive states of nature). However, differently from the aforementioned literature, agents share the same marginal rates of substitution for each given equilibrium aggregate output. Our contribution is to show that if managers internalize this equilibrium feature when forming their conjectures on firms' out-of-equilibrium market values, then efficiency is restored.
} 
undertakes one of two possible investment levels $a \in\{0,1\}$. This determines the probability over two possible date- 1 output levels, namely, $y_{\mathrm{L}}>0$ or $y_{\mathrm{H}}>y_{\mathrm{L}}$. The transition $a \mapsto Q_{\mathrm{H}}(a)$ represents the probability of producing $y_{\mathrm{H}}$ (success) under investment $a$. Investment is productive in the sense that $Q_{\mathrm{H}}(1)>Q_{\mathrm{H}}(0)$.

This technology has an alternative representation with three exogenous states of nature $\left\{\omega_{\mathrm{H}}, \omega_{\mathrm{M}}, \omega_{\mathrm{L}}\right\}$ and a random production production function

$$
f(a):=\left(f\left(\omega_{\mathrm{H}}, a\right), f\left(\omega_{\mathrm{M}}, a\right), f\left(\omega_{\mathrm{L}}, a\right)\right),
$$

such that $f(1):=\left(y_{\mathrm{H}}, y_{\mathrm{H}}, y_{\mathrm{L}}\right)$ and $f(0):=\left(y_{\mathrm{H}}, y_{\mathrm{L}}, y_{\mathrm{L}}\right)$. The output is always high when the exogenous state is $\omega_{\mathrm{H}}$, regardless the investment level. Analogously, it is always low in state $\omega_{\mathrm{L}}$. When the state is $\omega_{\mathrm{M}}$, the firm's production is high if, and only if, it has invested $a=1$. State probabilities $P(\omega)$ are exogenous and satisfy $P\left(\omega_{\mathrm{H}}\right)=Q_{\mathrm{H}}(0), P\left(\omega_{\mathrm{H}}\right)+P\left(\omega_{\mathrm{M}}\right)=Q_{\mathrm{H}}(1)$ and, hence, $\left.P\left(\omega_{\mathrm{L}}\right)=1-Q_{\mathrm{H}}(1)\right]^{3}$

At date 0 , the agent owns the firm and receives an initial endowment $e_{0}>1$. Preferences are represented by the expected utility

$$
u_{0}\left(x_{0}\right)+\mathbb{E}\left(u_{1}\left(x_{1}\right)\right),
$$

where the Bernoulli utility functions $u_{0}$ and $u_{1}$ are strictly increasing, continuously differentiable, strictly concave and satisfy the Inada condition at zero 4 We also assume that

$$
u_{0}^{\prime}\left(e_{0}-1\right)<u_{1}^{\prime}\left(y_{\mathrm{H}}\right)\left(y_{\mathrm{H}}-y_{\mathrm{L}}\right)\left[Q_{\mathrm{H}}(1)-Q_{\mathrm{H}}(0)\right] .
$$

Since Bernoulli functions are strictly concave, this condition ensures that investing is Pareto optimal 5

Two assets are traded in the financial markets: the firm's equity and a riskless bond. This market structure is incomplete with respect to exogenous uncertainty, as we have three states of nature but only two assets. Moreover, investment plans affect the individual ability to transfer wealth across primitive states, i.e., the spanning property of Ekern and Wilson (1974) is not satisfied $\sqrt{6}$ Therefore, we cannot follow the standard approach of general equilibrium theory to define unambiguously shareholder value for out-of-equilibrium investment decisions by means of a non-arbitrage argument.

\footnotetext{
${ }^{3}$ The probability space $(\Omega, P)$ with $\Omega:=\left\{\omega_{\mathrm{H}}, \omega_{\mathrm{M}}, \omega_{\mathrm{L}}\right\}$ represents the exogenous uncertainty since the probability measure $P$ does not depend on endogenous actions of the firm or the agent. The probability space $(Y, Q(a))$ with $Y:=\left\{y_{\mathrm{H}}, y_{\mathrm{L}}\right\}$ represents the endogenous uncertainty since the distribution $Q(a)$ depends on the investment level $a$.

${ }^{4}$ By that we mean $\lim _{x_{t} \rightarrow 0} u_{t}^{\prime}\left(x_{t}\right)=\infty$, for $t=0,1$.

${ }^{5}$ Strict concavity implies $u_{0}\left(e_{0}\right)-u_{0}\left(e_{0}-1\right)<u_{0}^{\prime}\left(e_{0}-1\right)$ and $u_{1}^{\prime}\left(y_{\mathrm{H}}\right)\left(y_{\mathrm{H}}-y_{\mathrm{L}}\right)<u_{1}\left(y_{\mathrm{H}}\right)-$ $u_{1}\left(y_{\mathrm{L}}\right)$. By combining theses inequalities with Equation [2.1), we obtain that $u_{0}\left(e_{0}\right)-u_{0}\left(e_{0}-1\right)<$ $\left(u_{1}\left(y_{\mathrm{H}}\right)-u_{1}\left(y_{\mathrm{L}}\right)\right)\left[Q_{\mathrm{H}}(1)-Q_{\mathrm{H}}(0)\right]$.

${ }^{6}$ When the equilibrium investment is $\bar{a}=1$, the equity and bond payoff vectors are respectively $\left(y_{\mathrm{H}}, y_{\mathrm{H}}, y_{\mathrm{L}}\right)$ and $(1,1,1)$. The production vector $\left(y_{\mathrm{H}}, y_{\mathrm{L}}, y_{\mathrm{L}}\right)$ associated with the out-ofequilibrium investment $a=0$ does not belong to the marketed space, in the sense that it cannot be generated by the assets payoff vectors $\left(y_{\mathrm{H}}, y_{\mathrm{H}}, y_{\mathrm{L}}\right)$ and $(1,1,1)$ respectively.
} 
Markets are not complete with respect to exogenous uncertainty, but they are complete with respect to endogenous uncertainty. Formally, in the pure exchange economy defined by some arbitrarily given investment level $a$, trade on the equity and bond markets allow the agent to perfectly insure against production risks since we only have two output levels. In particular, the consumption allocation associated to any competitive equilibrium is efficient (given the arbitrary investment decision $a$ ). In this simple example, the entire production is consumed by the single agent at equilibrium. Since there is only one firm, the aggregate output is either $z_{\mathrm{H}}:=y_{\mathrm{H}}$ or $z_{\mathrm{L}}:=y_{\mathrm{L}}$.

The limits of valuation by non-arbitrage Consider the pure exchange economy where the firm's investment is $\bar{a}=1$ and denote by $\bar{E}$ its equilibrium equity price and by $\bar{r}$ its equilibrium risk-free interest rate. Since markets are complete with respect to production risks, the contract paying one unit of the good contingent to aggregate output being $z$ can be implemented by trading the two available assets. Denoting by $\bar{\rho}(z)$ the non-arbitrage price of this contract, we have

$$
\bar{\rho}\left(z_{\mathrm{H}}\right)=\frac{1}{z_{\mathrm{H}}-z_{\mathrm{L}}}\left(\bar{E}-\frac{z_{\mathrm{L}}}{1+\bar{r}}\right) \quad \text { and } \quad \bar{\rho}\left(z_{\mathrm{L}}\right)=\frac{1}{z_{\mathrm{H}}-z_{\mathrm{L}}}\left(\frac{z_{\mathrm{H}}}{1+\bar{r}}-\bar{E}\right) .
$$

The standard definition of the competitive market value of the firm for the out-ofequilibrium investment $a=0$ is

$$
\Pi(0):=\sum_{\omega \in \Omega} \bar{p}(\omega) f(\omega, 0)=\bar{p}\left(\omega_{\mathrm{H}}\right) y_{\mathrm{H}}+\left[\bar{p}\left(\omega_{\mathrm{M}}\right)+\bar{p}\left(\omega_{\mathrm{L}}\right)\right] y_{\mathrm{L}},
$$

where $\bar{p}(\omega)$ is the non-arbitrage price of the contract paying one unit of the good contingent to the realization of the primitive state $\omega$. However, since markets are incomplete with respect to primitive states of nature, the valuation of these contracts is ambiguous. Formally, we cannot recover all the prices $\bar{p}(\omega)$ from the market prices $\bar{E}$ and $\bar{r}$ or, equivalently, from $\bar{\rho}\left(z_{\mathrm{H}}\right)$ and $\bar{\rho}\left(z_{\mathrm{L}}\right)$. Indeed, non-arbitrage only tells us that

$$
\bar{p}\left(\omega_{\mathrm{L}}\right)=\bar{\rho}\left(z_{\mathrm{L}}\right) \quad \text { and } \quad \bar{p}\left(\omega_{\mathrm{M}}\right)+\bar{p}\left(\omega_{\mathrm{H}}\right)=\bar{\rho}\left(z_{\mathrm{H}}\right) .
$$

The value of a large corporation Building on the market completeness with respect to endogenous uncertainty, Magill and Quinzii (2009) suggested a definition for the out-of-equilibrium market value of the firm. They started from the following description of the equilibrium market value $\bar{V}:=\bar{E}-\bar{a}$ of the firm, that is

$$
\bar{V}=y_{\mathrm{H}} \bar{\rho}\left(z_{\mathrm{H}}\right)+y_{\mathrm{L}} \bar{\rho}\left(z_{\mathrm{L}}\right)-\bar{a} .
$$

In order to make explicit the firm's investment decision in the above formula, we denote by $\bar{\chi}(z)$ the equilibrium stochastic discount factor defined by the equation

$$
\bar{\rho}\left(z_{s}\right)=\bar{\chi}\left(z_{s}\right) Q_{s}(\bar{a}), \quad \text { for all } s \in\{\mathrm{L}, \mathrm{H}\} \mathrm{\sqcup}^{7}
$$

\footnotetext{
${ }^{7}$ Consumption optimality implies $\bar{\chi}\left(z_{s}\right)=u_{1}^{\prime}\left(y_{s}\right) / u_{0}^{\prime}\left(e_{0}-\bar{a}\right)$, for $s \in\{\mathrm{L}, \mathrm{H}\}$.
} 
Therefore, the equilibrium value of the firm takes the following form

$$
\bar{V}=y_{\mathrm{H}} \bar{\chi}\left(z_{\mathrm{H}}\right) Q_{\mathrm{H}}(\bar{a})+y_{\mathrm{L}} \bar{\chi}\left(z_{\mathrm{L}}\right)\left(1-Q_{\mathrm{H}}(\bar{a})\right)-\bar{a} .
$$

When analyzing the decision of a non-marginal firm, Magill and Quinzii (2009, 2010) suggest to replace $\bar{a}=1$ in the above formula by $a=0$. This leads to the following conjecture

$$
M(a):=y_{\mathrm{H}} \bar{\chi}\left(z_{\mathrm{H}}\right) Q_{\mathrm{H}}(a)+y_{\mathrm{L}} \bar{\chi}\left(z_{\mathrm{L}}\right)\left(1-Q_{\mathrm{H}}(a)\right)-a
$$

of the firm's market value for the out-of-equilibrium investment $a \neq \bar{a}$. They show that the Pareto efficient level $\bar{a}=1$ does not necessarily maximize $M$. In our example, this result follows from the fact that the condition (2.1) (which implies Pareto efficiency of investment) may hold simultaneously with $M(0)>M(1)$ or, equivalently,

$$
u_{0}^{\prime}\left(e_{0}-1\right)>\left[y_{\mathrm{H}} u_{1}^{\prime}\left(y_{\mathrm{H}}\right)-y_{\mathrm{L}} u_{1}^{\prime}\left(y_{\mathrm{L}}\right)\right]\left[Q_{\mathrm{H}}(1)-Q_{\mathrm{H}}(0)\right] 8^{8}
$$

This inefficiency is due to a particular type of market power exerted by the firm. When choosing $M(0)$ as its conjecture for the out-of-equilibrium value, the firm takes into consideration that its investment decision affects the distribution of aggregated variables.

Remark 2.1. Magill and Quinzii (2009) analyze the decision of a non-negligible firm which is aware of the impact of its own production on the level of aggregate output. They assume that the firm's manager takes the stochastic discount factor function $z \mapsto \bar{\chi}(z)$ as given. They motivate this choice by arguing that "in the setting of capital markets, taking security prices as given is widely regarded as a good approximation, even for large corporations". We take the view that when corporations make their investment decisions, they take as given not only security prices but also the aggregate output.

A competitive conjecture for market value Defining a competitive conjecture for the out-of-equilibrium market value of the firm is not straightforward for an economy with output-contingent financial markets. Securities written on the aggregate output do not necessarily distinguish across primitive states of nature. Agents are aware that the equilibrium prices $\bar{\rho}(z)$ and the theoretical state prices $\bar{p}(\omega)$ are related to each other as stated in condition (2.2). However, market prices alone do not convey sufficient information for splitting $\bar{\rho}\left(z_{\mathrm{H}}\right)$ and $\bar{\rho}\left(z_{\mathrm{L}}\right)$ into $\bar{p}\left(\omega_{\mathrm{H}}\right), \bar{p}\left(\omega_{\mathrm{M}}\right)$,

\footnotetext{
${ }^{8}$ Since $u_{1}$ is strictly concave, we have $u_{1}^{\prime}\left(y_{\mathrm{H}}\right)<u_{1}^{\prime}\left(y_{\mathrm{L}}\right)$. This implies that

$$
\left[y_{\mathrm{H}} u_{1}^{\prime}\left(y_{\mathrm{H}}\right)-y_{\mathrm{L}} u_{1}^{\prime}\left(y_{\mathrm{L}}\right)\right]\left[Q_{\mathrm{H}}(1)-Q_{\mathrm{H}}(0)\right]<u_{1}^{\prime}\left(y_{\mathrm{H}}\right)\left(y_{\mathrm{H}}-y_{\mathrm{L}}\right)\left[Q_{\mathrm{H}}(1)-Q_{\mathrm{H}}(0)\right] .
$$
}

Therefore, we can always choose $u_{0}$ and $e_{0}$ such that $u_{0}^{\prime}\left(e_{0}-1\right)$ lies between the right-hand side and the left-hand side of the above inequality. 
and $\bar{p}\left(\omega_{\mathrm{L}}\right)$ in an unambiguous way. To overcome this issue, we ask firms and agents to anticipate the following important equilibrium feature when analyzing investment plans out of the equilibrium.

Markets are complete with respect to endogenous uncertainty. For any given investment level, the equilibrium ratio of marginal utilities are constant across primitive states of nature associated with the same aggregate output. This is to say that the agent's valuation of income streams contingent to a specific aggregate output is risk neutral. We propose to use this equilibrium feature to construct the shadow prices $\bar{p}(\omega)$ from the market prices $\bar{\rho}(z)$. When the investment is $\bar{a}=1$, we have

$$
\bar{p}\left(\omega_{\mathrm{L}}\right)=\bar{\rho}\left(z_{\mathrm{L}}\right) \quad \text { and } \quad \bar{p}\left(\omega_{\mathrm{H}}\right)+\bar{p}\left(\omega_{\mathrm{M}}\right)=\bar{\rho}\left(z_{\mathrm{H}}\right) .
$$

Under $\bar{a}=1$, the conditional state probabilities given the aggregate output $z_{\mathrm{H}}$ are

$$
P\left(\omega_{\mathrm{H}} \mid\left\{\omega_{\mathrm{H}}, \omega_{\mathrm{M}}\right\}\right)=\frac{P\left(\omega_{\mathrm{H}}\right)}{P\left(\omega_{\mathrm{H}}\right)+P\left(\omega_{\mathrm{M}}\right)} \quad \text { and } \quad P\left(\omega_{\mathrm{M}} \mid\left\{\omega_{\mathrm{H}}, \omega_{\mathrm{M}}\right\}\right)=\frac{P\left(\omega_{\mathrm{M}}\right)}{P\left(\omega_{\mathrm{H}}\right)+P\left(\omega_{\mathrm{M}}\right)} .
$$

Therefore, if we use a risk-neutral pricing conditional on $z_{\mathrm{H}}$, we obtain:

$$
\bar{p}\left(\omega_{\mathrm{H}}\right)=\bar{\rho}\left(z_{\mathrm{H}}\right) P\left(\omega_{\mathrm{H}} \mid\left\{\omega_{\mathrm{H}}, \omega_{\mathrm{M}}\right\}\right) \quad \text { and } \quad \bar{p}\left(\omega_{\mathrm{M}}\right)=\bar{\rho}\left(z_{\mathrm{H}}\right) P\left(\omega_{\mathrm{M}} \mid\left\{\omega_{\mathrm{H}}, \omega_{\mathrm{M}}\right\}\right) .
$$

This lead us to consider the conjecture $\Pi(a)$ for the firm's market value under investment $a \in\{0,1\}$ defined by:

$$
\begin{aligned}
\Pi(0) & :=y_{\mathrm{H}} \bar{p}\left(\omega_{\mathrm{H}}\right)+y_{\mathrm{L}} \bar{p}\left(\omega_{\mathrm{M}}\right)+y_{\mathrm{L}} \bar{p}\left(\omega_{\mathrm{L}}\right)-0 \\
& =\bar{\rho}\left(z_{\mathrm{H}}\right)\left[y_{\mathrm{H}} P\left(\omega_{\mathrm{H}} \mid\left\{\omega_{\mathrm{H}}, \omega_{\mathrm{M}}\right\}\right)+y_{\mathrm{L}} P\left(\omega_{\mathrm{M}} \mid\left\{\omega_{\mathrm{H}}, \omega_{\mathrm{M}}\right\}\right)\right]+\bar{\rho}\left(z_{\mathrm{L}}\right) y_{\mathrm{L}}
\end{aligned}
$$

and

$$
\begin{aligned}
\Pi(1) & :=y_{\mathrm{H}} \bar{p}\left(\omega_{\mathrm{H}}\right)+y_{\mathrm{H}} \bar{p}\left(\omega_{\mathrm{M}}\right)+y_{\mathrm{L}} \bar{p}\left(\omega_{\mathrm{L}}\right)-1 \\
& =y_{\mathrm{H}} \bar{\rho}\left(z_{\mathrm{H}}\right)+y_{\mathrm{L}} \bar{\rho}\left(z_{\mathrm{L}}\right)-1 \\
& =\bar{V} .
\end{aligned}
$$

It is then simple to verify that the Pareto optimal investment level $\bar{a}=1$ does in fact maximize the function $a \mapsto \Pi(a)$. We just need to notice that

$$
\Pi(1)-\Pi(0)=\frac{u_{1}^{\prime}\left(y_{\mathrm{H}}\right)}{u_{0}^{\prime}\left(e_{0}-1\right)}\left(y_{\mathrm{H}}-y_{\mathrm{L}}\right) P\left(\omega_{\mathrm{M}}\right)-1>0,
$$

where the last inequality follows from assumption 2.1 and the fact that $P\left(\omega_{\mathrm{M}}\right)=$ $Q_{\mathrm{H}}(1)-Q_{\mathrm{H}}(0)$.

There is an equivalent way to define price conjectures without relying explicitly on shadow (or conjectured) prices $\bar{p}(\omega)$ for the exogenous states of nature. Let $\widetilde{y}(a \mid z):=\mathbb{E}[f(a) \mid f(\bar{a})=z]$ be the firm's average production, under investment $a$, across states of nature for which the equilibrium aggregate output is $z$. We define the competitive conjecture for firm's value as

$$
V(a):=\widetilde{y}\left(a \mid z_{\mathrm{H}}\right) \rho\left(z_{\mathrm{H}}\right)+\widetilde{y}\left(a \mid z_{\mathrm{L}}\right) \rho\left(z_{\mathrm{L}}\right)-a .
$$


In this illustration, we have that $\widetilde{y}\left(0 \mid z_{\mathrm{H}}\right)=y_{\mathrm{H}} P\left(\omega_{\mathrm{H}} \mid\left\{\omega_{\mathrm{H}}, \omega_{\mathrm{M}}\right\}\right)+y_{\mathrm{L}} P\left(\omega_{\mathrm{M}} \mid\left\{\omega_{\mathrm{H}}, \omega_{\mathrm{M}}\right\}\right)$, $\widetilde{y}\left(0 \mid z_{\mathrm{L}}\right)=y_{\mathrm{L}}$, and then

$$
\begin{aligned}
V(0) & =\bar{\rho}\left(z_{\mathrm{H}}\right)\left[y_{\mathrm{H}} P\left(\omega_{\mathrm{H}} \mid\left\{\omega_{\mathrm{H}}, \omega_{\mathrm{M}}\right\}\right)+y_{\mathrm{L}} P\left(\omega_{\mathrm{M}} \mid\left\{\omega_{\mathrm{H}}, \omega_{\mathrm{M}}\right\}\right)\right]+\bar{\rho}\left(z_{\mathrm{L}}\right) y_{\mathrm{L}} \\
& =\Pi(0) .
\end{aligned}
$$

Moreover, we also have $\widetilde{y}\left(1 \mid z_{\mathrm{H}}\right)=y_{\mathrm{H}}, \widetilde{y}\left(1 \mid z_{\mathrm{L}}\right)=y_{\mathrm{L}}$, and then $V(1)=\bar{V}=\Pi(1)$.

\section{General model}

Consider an economy with two periods $t \in\{0,1\}$, a single good, a finite set $K$ of firms, and a finite set $I$ of consumers. At the initial date $(t=0)$, each firm $k$ selects an investment level $a^{k}$ from a set $A^{k} \subseteq \mathbb{R}_{+}$. Making no investment is always a possibility-i.e., $0 \in A^{k}$, for every $k$. At date 1 , they are exposed to exogenous shocks $\omega$ drawn from a probability space $(\Omega, \mathcal{F}, P)$. Events $B \in \mathcal{F}$ represent primitive causes which odds are represented by the exogenous probability $P(B)$. This probability is independent of consumers' and firms' actions.

\subsection{Technology}

The initial investment $a^{k}$ and the exogenous shock $\omega$ determine firm $k$ 's production $y^{k}=f^{k}\left(\omega, a^{k}\right)$ at date 1 from a set $Y^{k} \subseteq \mathbb{R}_{+}$. The production possibilities of the economy are represented by the family $f:=\left(f^{k}\right)_{k \in K}$ of non-decreasing random production functions

$$
f^{k}(\omega, \cdot): A^{k} \rightarrow Y^{k}
$$

We assume that, for each investment $a^{k}$, the function $\omega \mapsto f^{k}\left(\omega, a^{k}\right)$ is measurable and essentially bounded on $(\Omega, \mathcal{F}, P) \cdot{ }^{9}$

From this standard production-function framework, we derive the following alternative representation of the productive sector. Define the sets $A:=\prod_{k \in K} A^{k}$ and $Y:=\prod_{k \in K} Y^{k}$, their respective elements $a:=\left(a^{k}\right)_{k \in K}$ and $y:=\left(y^{k}\right)_{k \in K}$, and the transition probability $a \mapsto Q(a)$ given by

$$
Q(B, a):=P(\{f(a) \in B\}),
$$

for every Borel set $B \subseteq Y$ 10 The investment profile $a \in A$ undertaken at date 0 determines the joint probability $Q(a)$ of firms' random outcomes at date 1 .

\footnotetext{
${ }^{9}$ To fix ideas, we can take $\Omega$ to be the product space $\prod_{k \in K}\left(Y^{k}\right)^{A^{k}}$ and $\mathcal{F}$ to be the product $\otimes_{k \in K} \mathcal{B}^{k}$ of each Borelian $\sigma$-algebra $\mathcal{B}^{k}$ defined by the product topology of the space $\left(Y^{k}\right)^{A^{k}}$. The support of the probability $P$ is then assumed to be a subset of $\prod_{k \in K} N\left(A^{k}, Y^{k}\right)$, where $N\left(A^{k}, Y^{k}\right)$ is the set of non-decreasing functions from $A^{k}$ to $Y^{k}$.

${ }^{10}$ The set $\{f(a) \in B\}$ stands for $\{\omega \in \Omega: f(\omega, a) \in B\}$. Similar notation omitting $\omega$ is used throughout the paper.
} 
To represent aggregate production, we define the $\sigma$-operator to be

$$
\sigma y:=\sum_{k \in K} y^{k}, \quad \text { for all } y \in Y .
$$

The random aggregate production is then represented by the function $\omega \mapsto \sigma f(\omega, a)$. We let $Z:=\sum_{k \in K} Y^{k}$ denote the set of all possible aggregate outputs and derive the transition probability $a \mapsto \mu(a)$ by posing

$$
\mu(B, a):=P(\{\sigma f(a) \in B\}),
$$

for every Borel set $B \subseteq Z$. We assume that date- 1 output is bounded away from zero, in the sense that there exists $\varepsilon>0$ such that $\mu([\varepsilon, \infty), a)=1$, for every $a \in A$.

\section{$3.2 \quad$ Agents}

Each agent $i$ has initial resources consisting of an endowment $e_{0}^{i}>0$ at date 0 and the ownership shares $\delta_{k}^{i} \in[0,1]$ of each firm $k$, where $\sum_{i \in I} \delta_{k}^{i}=1$. Agents have no initial endowment at date 1 , so that all consumption in that period comes from the firms' output. Preferences are represented by a utility function that is separable across time and has the expected utility form for future risky consumption. Let $x_{0}^{i} \geqslant 0$ denote agent $i$ 's consumption at date 0 and $\gamma^{i}$ be a probability measure on $\mathbb{R}_{+}$that represents random consumption at date 1 . Agent $i$ 's expected utility function is given by

$$
u_{0}\left(x_{0}^{i}\right)+\int_{\mathbb{R}_{+}} u_{1}\left(x_{1}^{i}\right) \gamma^{i}\left(d x_{1}^{i}\right),
$$

where $u_{0}$ and $u_{1}$ are strictly increasing, continuously differentiable, and strictly concave functions which map $\mathbb{R}_{+}$into $[-\infty, \infty)$ and satisfy the Inada condition at zero.

Remark 3.1. The time separability of the expected utility and the cross-agent homogeneity of the Bernoulli utility functions are only assumed to simplify the notation. It is straightforward to extend all results in this paper to the case with heterogeneous Bernoulli utility functions $\left(x_{0}^{i}, x_{1}^{i}\right) \mapsto \nu^{i}\left(x_{0}^{i}, x_{1}^{i}\right)$.

\subsection{Competitive equilibrium for a given investment}

For sake of expositional clarity, we first define a competitive equilibrium for our output-contingent environment by taking the investment level of each firm as given. After understanding how agents insure each other, we analyze the problem of how firms choose their investments.

Different from the traditional Arrow-Debreu model, we do not consider contracts contingent on the realization of the primitive states of nature $\omega$. We assume that the probabilities and the economic consequences of the events in $\mathcal{F}$ are well-understood by firms and agents, but the costs of describing ex-ante each primitive state of 
nature and enforcing ex-post state-contingent contracts are too large. The only traded contracts are those based on firms' output. We consider two types of assets: the equity of each firm $k \in K$ traded in positive net supply; and securities in zero net supply representing bonds and all possible output-contingent derivatives.

Uncertainty only derives from production risks. Hence, an efficient allocation of risks among consumers (for a given vector of firms' investments) only requires that agents trade firms' equities and claims contingent on date- 1 aggregate output. At date 0 , for a given investment profile $a$, each agent $i$ chooses current consumption $x_{0}^{i} \in \mathbb{R}_{+}$, new equity holdings $\eta^{i} \in \mathbb{R}^{K}$ and a (Borel-measurable) contract $\theta^{i}: Z \rightarrow \mathbb{R}$ contingent on aggregate output such that

$$
x_{0}^{i}+\int_{Z} \theta^{i}(z) \rho(d z)+E \cdot \eta^{i} \leqslant e_{0}^{i}+(E-a) \cdot \delta^{i},
$$

where $E$ stands for the vector of equity prices, and $\rho$ is a positive measure on the Borel sets of $Z$ such that $\rho([0, z])$ represents the date- 0 price of the contract delivering one unit of consumption good contingent on the aggregate output being lower than or equal to $z$. At date 1, contingent on output profile $y$, agent $i$ consumes

$$
x_{1}^{i}(y):=\theta^{i}(\sigma y)+y \cdot \eta^{i} \geqslant 0 .
$$

Each agent $i$ maximizes the expected utility

$$
u_{0}\left(x_{0}^{i}\right)+\int_{Y} u_{1}\left(x_{1}^{i}(y)\right) Q(d y, a)
$$

among all individual plans $\left(x_{0}^{i}, x_{1}^{i}, \eta^{i}, \theta^{i}\right)$ satisfying the budget constraints 3.1 and $(3.2)$, for $Q(a)$-almost every $y$.

A financial equilibrium associated with a given investment profile $\bar{a}$ is a list $\left(\bar{E}, \bar{\rho},\left(\bar{x}_{0}, \bar{x}_{1}, \bar{\eta}, \bar{\theta}\right)\right)$, where $\left(\bar{x}_{0}, \bar{x}_{1}, \bar{\eta}, \bar{\theta}\right):=\left(\bar{x}_{0}^{i}, \bar{x}_{1}^{i}, \bar{\eta}^{i}, \bar{\theta}^{i}\right)_{i \in I}$ is a consumptionportfolio allocation such that:

(i) for every $i \in I$, the plan $\left(\bar{x}_{0}^{i}, \bar{x}_{1}^{i}, \bar{\eta}^{i}, \bar{\theta}^{i}\right)$ solves agent $i$ 's optimization problem given $(\bar{E}, \bar{\rho}, \bar{a})$;

(ii) the consumption markets clear, i.e.,

$$
\sum_{i \in I}\left(e_{0}^{i}-\bar{x}_{0}^{i}\right)=\sum_{k \in K} \bar{a}^{k}
$$

and

$$
\sum_{i \in I} \bar{x}_{1}^{i}(y)=\sigma y, \quad \text { for } Q(\bar{a}) \text {-almost every } y \text {; }
$$


(iii) the financial markets clear, i.e.,

$$
\sum_{i \in I} \bar{\eta}^{i}=\mathbf{1} \text { and } \quad \sum_{i \in I} \bar{\theta}^{i}(z)=0, \quad \text { for } \mu(\bar{a}) \text {-almost every } z
$$

An allocation $\left(\left(x_{0}, x_{1}\right), a\right)$ is a pair composed of a consumption allocation $\left(x_{0}, x_{1}\right)=\left(x_{0}^{i}, x_{1}^{i}\right)_{i \in I}$ and an investment profile $a=\left(a^{k}\right)_{k \in K}$. An allocation is said to be feasible if the consumption markets clear. An allocation $\left(\left(x_{0}, x_{1}\right), a\right)$ is said to Pareto dominate the allocation $\left(\left(\bar{x}_{0}, \bar{x}_{1}\right), \bar{a}\right)$ whenever

$$
u_{0}\left(x_{0}^{i}\right)+\int_{Y} u_{1}\left(x_{1}^{i}(y)\right) Q(d y, a) \geqslant u_{0}\left(\bar{x}_{0}^{i}\right)+\int_{Y} u_{1}\left(\bar{x}_{1}^{i}(y)\right) Q(d y, \bar{a}),
$$

for every agent $i$, with strict inequality for at least one agent $i$. An allocation $\left(\left(\bar{x}_{0}, \bar{x}_{1}\right), \bar{a}\right)$ is Pareto optimal if $\left(\left(\bar{x}_{0}, \bar{x}_{1}\right), \bar{a}\right)$ is feasible and there is no other feasible allocation $\left(\left(x_{0}, x_{1}\right), a\right)$ that Pareto dominates $\left(\left(\bar{x}_{0}, \bar{x}_{1}\right), \bar{a}\right)$. A consumption allocation $\left(\bar{x}_{0}, \bar{x}_{1}\right)$ is Pareto optimal for a given investment $\bar{a}$ if $\left(\left(\bar{x}_{0}, \bar{x}_{1}\right), \bar{a}\right)$ is feasible and there is no other feasible allocation $\left(\left(x_{0}, x_{1}\right), \bar{a}\right)$ with the same investment profile that Pareto dominates $\left(\left(\bar{x}_{0}, \bar{x}_{1}\right), \bar{a}\right)$. The next result shows that our market structure implements a Pareto optimal distribution of resources among consumers for any given investment profile 12

Proposition 3.1. Fix a financial equilibrium $\left(\bar{E}, \bar{\rho},\left(\bar{x}_{0}, \bar{x}_{1}, \bar{\eta}, \bar{\theta}\right)\right)$ associated with an arbitrary investment vector $\bar{a}$. The corresponding consumption allocation $\left(\bar{x}_{0}, \bar{x}_{1}\right)$ is Pareto optimal given $\bar{a}$.

The equilibrium measure $\bar{\rho}(d z)$ is absolutely continuous with respect to $\mu(d z, \bar{a})$. This is to say that there is a Borel-measurable function $\bar{\chi}: Z \rightarrow \mathbb{R}_{+}$(called the stochastic discount factor) such that:

$$
\bar{\rho}(d z)=\bar{\chi}(z) \mu(d z, \bar{a}) .
$$

Pareto optimality of the consumption allocation $\left(\bar{x}_{0}, \bar{x}_{1}\right)$ given $\bar{a}$ implies the individual consumption $\bar{x}_{1}^{i}(y)$ to be constant across output vectors $y$ generating the same aggregate output $\sigma y$. Therefore, there exist Borel-measurable functions $\bar{c}_{1}^{i}: Z \rightarrow \mathbb{R}_{+}$ such that $\bar{x}_{1}^{i}(y)=\bar{c}_{1}^{i}(\sigma y)$ for all $y$ and $i$. Since date- 1 aggregate production is bounded away from zero, our assumptions on the Bernoulli utilities imply that the ratio of marginal utilities equals the stochastic discount factor

$$
\frac{u_{1}^{\prime}\left(\bar{x}_{1}^{i}(y)\right)}{u_{0}^{\prime}\left(\bar{x}_{0}^{i}\right)}=\frac{u_{1}^{\prime}\left(\bar{c}_{1}^{i}(\sigma y)\right)}{u_{0}^{\prime}\left(\bar{x}_{0}^{i}\right)}=\bar{\chi}(\sigma y)
$$

for every $i$ and $y$. As a consequence, the market is risk neutral conditional on the aggregate output, and the equilibrium equity prices can be written as

$$
\bar{E}=\int_{Y} \bar{\chi}(\sigma y) y Q(d y, \bar{a}) .
$$

\footnotetext{
${ }^{11}$ The term 1 represents the $K$-dimensional vector of ones.

${ }^{12}$ The proof follows from standard arguments and the details are postponed to Appendix A.1
} 


\section{The market value of each firm}

We now analyze how investment levels are chosen by firms in equilibrium. Each firm is assumed to be small relative to the aggregate economy and does not seek to manipulate prices. Under these competitive conditions, a natural objective function for a firm to maximize is its market value. When markets are complete with respect to primitive states (like in the standard Arrow-Debreu framework), the Arrow prices $\bar{p}(B)$ associated with any $(\mathcal{F}$-measurable) primitive event $B \subseteq \Omega$ are quoted in the market. Firm $k$ 's manager can take these prices as given and use them to compute the following conjectured equity value

$$
E^{k}\left(a^{k}\right):=\int_{\Omega} f^{k}\left(\omega, a^{k}\right) \bar{p}(d \omega)
$$

associated with any out-of-equilibrium investment $a^{k}$. In that case, maximizing the standard competitive market value

$$
\Pi^{k}\left(a^{k}\right):=E^{k}\left(a^{k}\right)-a^{k}=\int_{\Omega} f^{k}\left(\omega, a^{k}\right) \bar{p}(d \omega)-a^{k}
$$

leads to Pareto optimality.

In the absence of securities whose payoffs are contingent on exogenous events, a deep issue arises: how firms should assess their equity value for production plans different from the equilibrium ones? Or equivalently, how can we define the conjecture $E^{k}\left(a^{k}\right)$ when the prices $\bar{p}(d \omega)$ are not available?

\subsection{Competitive conjectures conditional on aggregate production}

The equilibrium prices $\bar{\rho}(d z)$ allow us to price by non-arbitrage any (bounded) contingent claim written on the aggregate output. The non-arbitrage price of a claim represented by a bounded function $h: Z \rightarrow \mathbb{R}$ is

$$
\int_{Z} h(z) \bar{\rho}(d z)
$$

However, we are also interested in pricing random variables that are not measurable with respect to the equilibrium aggregate output ${ }^{13}$ The question at issue is then how to extend this pricing formula to the space of bounded random variables.

We recall that markets are incomplete and, then, there are infinitely many stochastic discount factors on $\Omega$ that are consistent with the equilibrium prices $\bar{\rho}$. These discount factors, however, do not generate the same value for random variables that are not $\sigma f(\bar{a})$-measurable.

\footnotetext{
${ }^{13}$ For instance, since the spanning property of Ekern and Wilson (1974) is not necessarily satisfied, the out-of-equilibrium production claim $f^{k}\left(a^{k}\right)$, may not be $\sigma f(\overline{\bar{a}})$-measurable, when $a^{k} \neq \bar{a}^{k}$.
} 
We propose to assume that firms and agents rationally anticipate the equilibrium property that the market is risk neutral conditional on aggregate output - as follows from Proposition 3.1 and equation (3.7). Combining this with standard non-arbitrage valuation leads to the following definition of conditional risk-neutral valuation $\widetilde{S}$. For any bounded random variable $g: \Omega \rightarrow \mathbb{R}$ on $(\Omega, \mathcal{F}, P)$,

$$
\widetilde{S}(g):=\int_{Z} h(z) \bar{\rho}(d z)
$$

where $h(z):=\mathbb{E}[g \mid \sigma f(\bar{a})=z]{ }^{14}$ In other words, among the many possible stochastic discount factors, we take the one that is constant across states $\omega$ that are associated (at equilibrium) with the same aggregate output $z$.

Under this conditional risk-neutral valuation, firms and agents hold the following conjecture for the value of the out-of-equilibrium claim $f^{k}\left(a^{k}\right)$ :

$$
\widetilde{E}^{k}\left(a^{k}\right):=\widetilde{S}\left(f^{k}\left(a^{k}\right)\right)=\int_{Z} \widetilde{y}^{k}\left(a^{k} \mid z\right) \bar{\rho}(d z)
$$

where

$$
\widetilde{y}^{k}\left(a^{k} \mid z\right):=\mathbb{E}\left[f^{k}\left(a^{k}\right) \mid \sigma f(\bar{a})=z\right]
$$

is the conditional expected output associated with the out-of-equilibrium investment $a^{k}$ given the equilibrium aggregate output $z$. The value of the firm consistent with this pricing rule is given by

$$
V^{k}\left(a^{k}\right):=\widetilde{E}^{k}\left(a^{k}\right)-a^{k}=\int_{Z} \widetilde{y}^{k}\left(a^{k} \mid z\right) \bar{\rho}(d z)-a^{k} .
$$

The key behavioral assumption behind Eqs. 4.2, 4.3), and 4.4 is that firms and agents take prices as given and form competitive beliefs about the conditional expected production under different out-of-equilibrium investment levels. They understand that firm $k$ 's output becomes the random variable $\omega \mapsto f^{k}\left(\omega, a^{k}\right)$ whenever it invests $a^{k}$. However, they also believe that firm $k$ 's decisions do not affect the likelihood of aggregate production and, therefore, compute expected production $\widetilde{y}^{k}\left(a^{k} \mid z\right)$ conditional on the event $\{\sigma f(\bar{a})=z\}$. The conditioning event is evaluated at the equilibrium investment vector, which includes the investment choice of firm $k$. One could metaphorically think about this as if there was a continuum of firms so that the term $\widetilde{y}^{k}\left(a^{k} \mid z\right)$ represented the conditional expected output when a firm invested $a^{k}$ while all other infinite firms invested the equilibrium level.

\footnotetext{
${ }^{14}$ By this we mean that $h: Z \rightarrow \mathbb{R}$ is a Borel function such that $\mathbb{E}[g \mid \sigma f(\bar{a})]=h(\sigma f(\bar{a}))$, almost everywhere.
} 
Remark 4.1 (Correctness at equilibrium). Our competitive price conjectures coincide with the equilibrium prices. Formally, we have

$$
\begin{aligned}
\widetilde{E}^{k}\left(\bar{a}^{k}\right) & =\int_{Z} \widetilde{y}^{k}\left(\bar{a}^{k} \mid z\right) \bar{\rho}(d z) \\
& =\int_{Z} \widetilde{y}^{k}\left(\bar{a}^{k} \mid z\right) \bar{\chi}(z) \mu(d z, \bar{a}) \\
& =\int_{Y} \bar{\chi}(\sigma y) \widetilde{y}^{k}\left(\bar{a}^{k} \mid \sigma y\right) Q(d y, \bar{a}) \\
& =\int_{Y} \bar{\chi}(\sigma y) y^{k} Q(d y, \bar{a}) \\
& =\bar{E}^{k},
\end{aligned}
$$

where these equalities follow from equations $3.8,4.2$, and 4.3 .

\subsection{Efficiency}

We turn now to show the Pareto optimality of any allocation $\left(\left(\bar{x}_{0}, \bar{x}_{1}\right), \bar{a}\right)$ derived from a financial equilibrium in which each investment $\bar{a}^{k}$ maximizes the competitive market value $V^{k}$. We have argued before that the impossibility to trade assets contingent on primitive states is an essential incompleteness of markets from the perspective of firms. Although consumers do not need to trade securities contingent on primitive states to perfectly share idiosyncratic risks, firms need the information embedded in the state-contingent prices $\bar{p}$ in order to compute the competitive present value $\Pi^{k}\left(a^{k}\right)$ associated with out-of-equilibrium investment plans $a^{k} \neq \bar{a}^{k}$, as defined in equation (4.1). We show that this incompleteness can be overcome if firms believe the market is risk neutral conditional on aggregate output, or equivalently, if they hold the competitive price conjectures $\widetilde{E}^{k}\left(a^{k}\right)$. To prove this, we first show that our definition of competitive conjectures provides a connection between the standard Arrow-Debreu concept of competitive equilibrium and our definition of financial equilibrium.

We recall that an Arrow-Debreu equilibrium is a list $\left(\bar{p},\left(\bar{\xi}_{0}, \bar{\xi}_{1}\right), \bar{a}\right)$ composed of: (i) a positive measure $\bar{p}$ on $(\Omega, \mathcal{F})$ representing state-contingent prices; (ii) an allocation $\left(\bar{\xi}_{0}, \bar{\xi}_{1}\right):=\left(\bar{\xi}_{0}^{i}, \bar{\xi}_{1}^{i}\right)_{i \in I}$ of consumption plans, where $\bar{\xi}_{0}^{i} \geqslant 0$ and $\bar{\xi}_{1}^{i}: \Omega \rightarrow \mathbb{R}_{+}$ is a random variable; and (iii) an investment vector $\bar{a}:=\left(\bar{a}^{k}\right)_{k \in K}$ such that:

(a) the allocation $\left(\left(\bar{\xi}_{0}, \bar{\xi}_{1}\right), \bar{a}\right)$ is feasible, in the sense that

$$
\sum_{i \in I} e_{0}^{i}-\bar{\xi}_{0}^{i}=\sum_{k \in K} \bar{a}^{k}
$$

and

$$
\sum_{i \in I} \bar{\xi}_{1}^{i}(\omega)=\sum_{k \in K} f^{k}\left(\omega, \bar{a}^{k}\right), \quad \text { for } P \text {-almost every } \omega \in \Omega
$$


(b) for each firm $k$, the investment $\bar{a}^{k}$ maximizes the present-value function

$$
\Pi^{k}\left(a^{k}\right):=\int_{\Omega} f^{k}\left(\omega, a^{k}\right) \bar{p}(d \omega)-a^{k}
$$

(c) for each agent $i$, the consumption plan $\left(\bar{\xi}_{0}^{i}, \bar{\xi}_{1}^{i}\right)$ maximizes the expected utility

$$
u_{0}\left(\xi_{0}^{i}\right)+\int_{\Omega} u_{1}\left(\xi_{1}^{i}(\omega)\right) P(d \omega)
$$

subject to the present-value budget constraint

$$
\xi_{0}^{i}+\int_{\Omega} \xi_{1}^{i}(\omega) \bar{p}(d \omega) \leqslant e_{0}^{i}+\Pi(\bar{a}) \cdot \delta^{i},
$$

where $\Pi(\bar{a}):=\left(\Pi\left(\bar{a}^{k}\right)\right)_{k \in K}$.

Proposition 4.1. There exists an Arrow-Debreu equilibrium $\left(\bar{p},\left(\bar{\xi}_{0}, \bar{\xi}_{1}\right), \bar{a}\right)$ if, and only if, there exists a financial equilibrium $\left(\bar{E}, \bar{\rho},\left(\bar{x}_{0}, \bar{x}_{1}, \bar{\eta}, \bar{\theta}\right)\right)$ associated with the investment vector $\bar{a}$ such that, for each $k, \bar{a}^{k}$ maximizes the competitive conjecture $V^{k}$.

The proof of this proposition is given in Appendix A.2. We sketch the arguments here. It consists in constructing the elements of a given equilibrium concept from the elements describing the alternative equilibrium. If $\left(\bar{p},\left(\bar{\xi}_{0}, \bar{\xi}_{1}\right), \bar{a}\right)$ is an Arrow-Debreu equilibrium, it follows from standard arguments that the consumption allocation at $t=1$ only depends on aggregate resources, i.e., there are Borel-measurable functions $\bar{c}_{1}^{i}: Z \rightarrow \mathbb{R}_{+}$such that $\bar{\xi}_{1}^{i}(\omega)=\bar{c}_{1}^{i}(\sigma f(\omega, \bar{a}))$, for all $\omega$ and $i$. We define $\left(\bar{x}_{0}, \bar{x}_{1}\right)$ by posing $\bar{x}_{0}^{i}:=\bar{\xi}_{0}^{i}$ and $\bar{x}_{1}^{i}(y):=\bar{c}_{1}^{i}(\sigma y)$ for each $y$ and $i$. Since $\bar{\xi}_{1}^{i}$ is $\sigma f(\bar{a})$-measurable, the contingent consumption $\bar{x}_{1}^{i}$ can be implemented by some portfolio $\left(\bar{\theta}^{i}, \bar{\eta}^{i}\right)$. Asset prices are defined using the standard present value pricing rule:

$$
\bar{\rho}(d z):=\bar{\chi}(z) \mu(d z, \bar{a}) \quad \text { and } \quad \bar{E}:=\int_{\Omega} f(\omega, \bar{a}) \bar{p}(d \omega)
$$

where $\bar{\chi}(z)=u_{1}^{\prime}\left(\bar{c}_{1}^{i}(z)\right) / u_{0}^{\prime}\left(\bar{\xi}_{0}^{i}\right)$ is the equilibrium stochastic discount factor. Finally, by the law of iterated expectations, we get that the Arrow-Debreu present value $\Pi^{k}\left(a^{k}\right)$ of the out-of-equilibrium equity coincides with our definition $V^{k}\left(a^{k}\right)$ of competitive conjecture:

$$
\begin{aligned}
\Pi^{k}\left(a^{k}\right) & :=\int_{\Omega} f^{k}\left(a^{k}\right) \bar{p}(d \omega)-a^{k} \\
& =\int_{\Omega} \mathbb{E}\left[f^{k}\left(a^{k}\right) \mid \sigma f(\bar{a})\right] \bar{p}(d \omega)-a^{k} \\
& =\int_{Z} \widetilde{y}^{k}\left(a^{k} \mid z\right) \bar{\rho}(d z)-a^{k} \\
& =: V^{k}\left(a^{k}\right) .
\end{aligned}
$$


Conversely, let $\left(\bar{E}, \bar{\rho},\left(\bar{x}_{0}, \bar{x}_{1}, \bar{\eta}, \bar{\theta}\right)\right)$ be a financial equilibrium associated with the investment vector $\bar{a}$ such that, for each $k, \bar{a}^{k}$ maximizes the competitive conjecture $V^{k}$. Recall from Proposition 3.1 that there are Borel-measurable functions $\bar{c}_{1}^{i}: Z \rightarrow \mathbb{R}_{+}$ such that $\bar{x}_{1}^{i}(y)=\bar{c}_{1}^{i}(\sigma y)$, for all $y$ and $i$. We then define the state-contingent consumption allocation $\left(\bar{\xi}_{0}, \bar{\xi}_{1}\right)$ by posing $\bar{\xi}_{0}^{i}:=\bar{x}_{0}^{i}$ and $\bar{\xi}_{1}^{i}:=\bar{c}_{1}^{i}(\sigma f(\bar{a}))$. The novelty of our approach is to use conditional risk-neutral valuation in order to define the state prices $\bar{p}$ by posing

$$
\frac{d \bar{p}}{d P}(\omega):=\frac{d \bar{\rho}}{d \mu(\bar{a})}(\sigma f(\omega, \bar{a}))
$$

or, equivalently, $\bar{p}(d \omega)=\bar{\chi}(\sigma f(\omega, \bar{a})) P(d \omega)$, where $\bar{\chi}(\cdot)$ is the equilibrium stochastic discount factor defined by the equation $\bar{\rho}(d z)=\bar{\chi}(z) \mu(d z, \bar{a})$. This definition of $\bar{p}$ allows us to go from the bottom to the top in equation (4.8).

The First Welfare Theorem holds true in the Arrow-Debreu framework, given the baseline assumptions of our model. It then follows from Proposition 4.1 that the allocation composed of an investment vector that maximizes each firm's competitive conjecture for out-of-equilibrium market value and the consumption profile from the corresponding financial equilibrium is Pareto optimal. This is proven in our next result.

Theorem 4.1. Let $\left(\bar{E}, \bar{\rho},\left(\bar{x}_{0}, \bar{x}_{1}, \bar{\eta}, \bar{\theta}\right)\right)$ be a financial equilibrium associated with an investment vector $\bar{a}$. If $\bar{a}^{k}$ maximizes $V^{k}$, for all $k$, then the allocation $\left(\left(\bar{x}_{0}, \bar{x}_{1}\right), \bar{a}\right)$ is Pareto optimal.

Proof. Take the financial equilibrium $\left(\bar{E}, \bar{\rho},\left(\bar{x}_{0}, \bar{x}_{1}, \bar{\eta}, \bar{\theta}\right)\right)$ associated with $\bar{a}$. Consider the corresponding Arrow-Debreu equilibrium $\left(\bar{p},\left(\bar{\xi}_{0}, \bar{\xi}_{1}\right), \bar{a}\right)$ defined by Proposition 4.1. Assume then, by way of contradiction, that there is an alternative outputcontingent feasible allocation $\left(\left(x_{0}, x_{1}\right), a\right)$ which Pareto dominates $\left(\left(\bar{x}_{0}, \bar{x}_{1}\right), \bar{a}\right)$. For each $i$, define the state-contingent consumption plan $\left(\xi_{0}^{i}, \xi_{1}^{i}\right)$ by posing $\xi_{0}^{i}:=x_{0}^{i}$ and $\xi_{1}^{i}(\omega):=x_{1}^{i}(f(\omega, a))$, for every $\omega$. The state-contingent allocation $\left(\left(\xi_{0}, \xi_{1}\right), a\right)$ satisfies the feasibility constraints (4.5) and (4.6). Moreover, we have

$$
\begin{aligned}
u_{0}\left(\xi_{0}^{i}\right)+\int_{\Omega} u_{1}\left(\xi_{1}^{i}(\omega)\right) P(d \omega) & =u_{0}\left(x_{0}^{i}\right)+\int_{Y} u_{1}\left(x_{1}^{i}(y)\right) Q(d y, a) \\
& \geqslant u_{0}\left(\bar{x}_{0}^{i}\right)+\int_{Y} u_{1}\left(\bar{x}_{1}^{i}(y)\right) Q(d y, \bar{a}) \\
& =u_{0}\left(\bar{\xi}_{0}^{i}\right)+\int_{\Omega} u_{1}\left(\bar{\xi}_{1}^{i}(\omega)\right) P(d \omega),
\end{aligned}
$$

where the inequality is strict for at least one agent $i$. This means that the allocation $\left(\left(\xi_{0}, \xi_{1}\right), a\right)$ Pareto dominates $\left(\left(\bar{\xi}_{0}, \bar{\xi}_{1}\right), \bar{a}\right)$, which contradicts the First Welfare Theorem applied to the Arrow-Debreu equilibrium $\left(\bar{p},\left(\bar{\xi}_{0}, \bar{\xi}_{1}\right), \bar{a}\right)$. 


\section{Some important discussions}

We use this section to discuss the limits of our results, comment on the existence of a competitive equilibrium, and compare our definition of competitive valuation with an alternative concept used in the literature. We start by stressing the importance of our key assumptions.

\subsection{About our assumptions}

Since the focus of this paper is the efficiency of firms' investment decisions, we restrict attention to security markets that implement an efficient consumption allocation in a competitive exchange equilibrium for fixed and known investment decisions by firms (efficiency of exchange). We have assumed that: (a) agents' preferences are represented by discounted expected utility with state-independent Bernoulli functions; (b) their endowments at the second date are deterministic; (c) agents agree on the probability distribution over the exogenous shocks $\omega$. Under these assumptions, efficiency of exchange follows through if financial markets allow consumers to trade firms' equities and make consumption plans contingent on aggregate output. Consumption risks become only associated with the variability of the aggregate output.

Efficiency of exchange is maintained if we relax these three assumptions and assume that financial markets are sufficiently rich to span the uncertainty in the outcomes of the firms, for each possible investment profile 15 However, our definition of the competitive conjecture for the value of the firm depends on assumption (c) and cannot be easily extended to environments in which agents' have heterogeneous expectations over the exogenous shocks. This is because using the conditional riskneutral valuation to infer shadow prices for exogenous states may lead to heterogeneous out-of-equilibrium conjectures among agents with heterogeneous expectations.

We have also focused on a model with a single good and two dates. These modeling choices are only for the sake of simplicity. Our results can be extended to environments with finitely many goods and periods as far as the financial structure ensures efficiency of exchange.

\subsection{About existence}

The objective of this paper is to investigate whether the maximization of a suitably defined conjecture of competitive market value leads to efficient investment decisions by firms, even if investors can only write contracts on observable output

\footnotetext{
${ }^{15}$ This condition is called "complete spanning" in Magill and Quinzii (2010). It means that it is possible (at a cost) to find a portfolio of bonds, equity contracts and derivatives whose payoff is one unit if a given profile of outcomes for the firms is realized, and nothing otherwise. As Ross (1976) showed, in a two-period model this is always possible if a sufficient number of options are introduced.
} 
(which distribution of risk is endogenous). An important related issue is existence of a competitive equilibrium where firms maximize the corresponding competitive market value.

Given an arbitrary investment profile $a$, existence of a competitive financial equilibrium is assured by our assumptions on preferences and positiveness of date- 0 endowments and of date- 1 production outcomes. In addition to that, if the sets $A^{k}$ were convex and the production functions $a^{k} \mapsto f^{k}\left(\omega, a^{k}\right)$ were continuous and concave on $A^{k}$ (for every $\omega$ ), then we could assure existence of a competitive financial equilibrium associated with an investment profile $\bar{a}$ that maximizes each firm's competitive market value $V^{k}$. This follows from Proposition 4.1 coupled with classic theorems on existence of Arrow-Debreu equilibrium - see Bewley (1972).

Remark 5.1 (Finitely many states). When the support of the probability $P$ is finite, the investment sets $A^{k}$ are convex, and the production functions $f^{k}$ are concave, then our assumption that securities' markets are complete with respect to aggregate output may (generically) yield complete markets with respect to the primitive states ${ }^{16}$ This feature is not generic when $A^{k}$ is finite and also does not appear when we have a continuum of primitive states of nature. We refer the reader to Appendix A.3 for a simple technology for which, given any output profile $y$ and investment vector $a$, there is a continuum of states $\omega$ satisfying $f(\omega, a)=y$.

Continuum of firms Among the many technologies that do not satisfy the general assumptions for existence of an Arrow-Debreu equilibrium, there is one that deserves particular attention. The benchmark production model in contract theory is such that each firm either succeeds or fails to produce a certain amount of output, and the probability of success increases with the firm's investment. This success-or-failure technology is represented by a non-convex production function and non-existence problems may arise.

A traditional approach to overcome this issue considers a continuum of ex-ante identical firms with i.i.d. production draws. In this case, all variation in output that underlies this particular technology is eliminated, and the objective of the firm ceases to be an issue. In a supplementary material, we present a model with a continuum of identical firms and perfectly correlated success-or-failure shocks. ${ }^{17}$ We explicitly compute an equilibrium under specific assumptions and also derive a general existence result. This illustrates an interesting way to keep variability in the (average) aggregate output while smoothing non-convexities through a continuum of firms. Notice also that modelling the productive sector with many small firms is consistent with the behavioral assumptions used along the paper.

\footnotetext{
${ }^{16}$ Indeed, concavity of the production function leads to a continuum of possible outcomes. Completeness with respect to aggregate output then requires (infinitely) many more securities than primitive states. We thank Martine Quinzii and Michael Magill for pointing this out.

${ }^{17}$ For reference, see Braido and Martins-da-Rocha (2017).
} 


\subsection{Strategic conjectures}

When analyzing the decision of non-marginal firms, Magill and Quinzii (2009, 2010) define the following "competitive" conjecture for the value of a firm:

$$
M^{k}\left(a^{k}\right):=\int_{Y} \bar{\chi}(\sigma y) y^{k} Q\left(d y,\left(a^{k}, \bar{a}^{-k}\right)\right)-a^{k},
$$

where $\left(a^{k}, \bar{a}^{-k}\right)$ represents a vector in which the $k$-th entry of $\bar{a}$ is replaced by $a^{k}$. Each firm $k$ takes as given the equilibrium stochastic discount factor $\bar{\chi}(z)$ conditional on each aggregate output $z$ and the investment vector $\bar{a}^{-k}$ of all other firms. We have that $V^{k}\left(\bar{a}^{k}\right)=M^{k}\left(\bar{a}^{k}\right)$ at any given financial equilibrium $\left(\bar{E}, \bar{\rho},\left(\bar{x}_{0}, \bar{x}_{1}, \bar{\eta}, \bar{\theta}\right)\right)$ associated with $\bar{a}$. However, $M^{k}\left(a^{k}\right)$ typically differs from our definition of competitive market value $V^{k}\left(a^{k}\right)$ for out-of-equilibrium investments $a^{k} \neq \bar{a}^{k}$.

The equilibrium in which each firm $k$ sets an investment $a^{k}$ to maximize $M^{k}\left(a^{k}\right)$ is not necessarily Pareto optimal. This may be surprising since agents display some competitive behavior by taking as given stochastic discount factors. However, by analyzing equation (5.1), one realizes that firm $k$ anticipates the impact of the investment $a^{k}$ over the probability distribution $Q$, which turns out to affect the value of all other firms through the probability $Q\left(d y,\left(a^{k}, \bar{a}^{-k}\right)\right)$. To assess this issue from a different perspective, we use the exogenous shocks to write

$$
M^{k}\left(a^{k}\right)=\int_{\Omega} f^{k}\left(\omega, a^{k}\right) \widetilde{p}^{k}\left(d \omega, a^{k}\right)-a^{k},
$$

where

$$
\widetilde{p}^{k}\left(d \omega, a^{k}\right):=\bar{\chi}\left(\sigma f\left(\omega,\left(a^{k}, \bar{a}^{-k}\right)\right)\right) P(d \omega) .
$$

Recall that if state-contingent claims were introduced in the market, all consumers would just be indifferent to buying or selling them if prices satisfied $\bar{p}(d \omega)=$ $\bar{\chi}(\sigma f(\omega, \bar{a})) P(d \omega)$. Therefore, we can interpret $\bar{p}(d \omega)$ as the competitive market shadow price for event $d \omega \in \mathcal{F}$. By replacing $\bar{p}(d \omega)$ with $\widetilde{p}^{k}\left(d \omega, a^{k}\right)$, firm $k$ 's manager implicitly anticipates the impact of her investment decisions over the aggregate output distribution and manipulates the underlying state prices that affect the market values of all firms. The inefficiencies associated to the conjecture $M^{k}$ are therefore due to the strategic behavior of the firm and are not related to market incompleteness as in the models analyzed by Geanakoplos and Polemarchakis (1986). Actually, even if all state-contingent claims were available for trade, inefficiency would still arise if firms exerted the same market power through its investment decisions - using the price measure $\widetilde{p}^{k}\left(d \omega, a^{k}\right)$ instead of the equilibrium price $\bar{p}(d \omega)$ to compute price conjectures.

\section{Presenting the main point in the CAPM setup}

Let us now illustrate our main contribution in an environment that is widely used in financial economics. For this, we adapt the CAPM environment described 
in Magill and Quinzii (1996), Chapter 3. There are two periods $t \in\{0,1\}$, one good, and finitely many firms and investors. Uncertainty is represented by an objective probability $P$ on a finite set $\Omega$ of primitive states of nature. We consider the simple case where only firm 1 has an exposure-to-risk decision. In the initial period, this firm chooses an investment level $a \in[0,1]$ that determines its output next period, according to a bounded random function $f^{1}(a)$. The production of all other firms is random and not related with the investment $a$. We use $\sigma f(a)$ to represent the sum of all productions ${ }^{18}$ The variance $\operatorname{var}(\sigma f(a))$ of the aggregate output is strictly positive, for every $a$.

Investors hold positive initial endowments and own shares of each firm. The current earning of investor $i$ is given by a real number $\xi_{0}^{i}$ and the future random earnings are represented by a random variable $\xi_{1}^{i}$. These earnings are ranked by

$$
v_{0}\left(\xi_{0}^{i}\right)+\mathbb{E}\left[v_{1}\left(\xi_{1}^{i}\right)\right],
$$

where the functions $v_{0}$ and $v_{1}$ are strictly increasing (on the relevant part of the domain), continuously differentiable, strictly concave, and such that $\mathbb{E}\left[v_{1}\left(\xi_{1}^{i}\right)\right]$ has a mean-variance representation 19

The only traded assets are a riskless bond in zero net supply and firms' equities in positive net supply. Markets are incomplete as there are only three assets and possibly more than three states in $\Omega$. Nonetheless, thanks to the mean-variance preference, for any arbitrary investment $\bar{a}$, the competitive equilibrium in the bondequity markets ensures a Pareto optimal distribution $\left(\bar{\xi}_{0}^{i}, \bar{\xi}_{1}^{i}\right)_{i \in I}$ of the available resources among investors. Moreover, there is also a discount factor $\bar{\chi}$ that is an affine function of aggregate output. Formally, there exist two strictly positive constants $\bar{\gamma}$ and $\bar{\lambda}$ such that, for every investor $i$,

$$
\frac{v_{1}^{\prime}\left(\bar{\xi}_{1}^{i}\right)}{v_{0}^{\prime}\left(\bar{\xi}_{0}^{i}\right)}=\bar{\chi}(\sigma f(\bar{a})),
$$

where

$$
\bar{\chi}(z)=\bar{\gamma}-\bar{\lambda} z
$$

for any possible equilibrium aggregate output $z$. The market value $\bar{E}^{1}$ of firm 1 is then given by the CAPM asset pricing equation

$$
\bar{E}^{1}=\frac{\mathbb{E}\left[f^{1}(\bar{a})\right]}{1+\bar{r}}-\bar{\lambda} \operatorname{cov}\left(f^{1}(\bar{a}), \sigma f(\bar{a})\right),
$$

where $\bar{r}$ is the equilibrium risk-free rate and $\bar{\lambda}$ is interpreted as the market price per unit of risk 20

\footnotetext{
${ }^{18}$ Formally, if we have $K$ firms, then $\sigma f(a):=f^{1}(a)+f^{2}+\ldots+f^{K}$, where $f^{k}$ is a random variable, for any $k \neq 1$.

${ }^{19}$ That is, there exists a function $\phi: \mathbb{R} \times \mathbb{R}_{+} \rightarrow \mathbb{R}$ such that $\mathbb{E}\left[v_{1}\left(\xi_{1}^{i}\right)\right]=\phi\left(\mathbb{E}\left[\xi_{1}^{i}\right]\right.$, var $\left.\left[\xi_{1}^{i}\right]\right)$, where $\phi$ is increasing in the first variable and decreasing in the second.

${ }^{20}$ These results follow from Magill and Quinzii (1996), Theorem 17.3.
} 
In this context, we ask how firm 1 should make its investment decision. Will the objective of this firm lead to Pareto efficiency in the production side? If markets were complete, then firms and investors could use the information contained in asset prices to infer the equilibrium Arrow price $\bar{p}(\omega)$, for each exogenous state $\omega$. In this case, any investment that maximizes the Arrow-Debreu present value of firm 1, i.e.,

$$
a \mapsto \Pi^{1}(a):=\sum_{\omega \in \Omega} \bar{p}(\omega) f^{1}(\omega, a)-a,
$$

is Pareto efficient and unanimously supported by the stockholders. But how to compute $a \mapsto \Pi^{1}(a)$ when Arrow prices are not available? Since the bond-equity markets are incomplete, there are infinitely many stochastic discount factors leading to the same equilibrium prices but to different evaluations about out-of-equilibrium investment plans $a \neq \bar{a}$.

We propose to build on the CAPM asset pricing equation 6.1 to define conjectures about how the market would value the firm's equity under an alternative investment level $a \neq \bar{a}$. When making out-of-equilibrium price conjectures, we assume that the manager acts competitively in the following sense: he takes the risk-free interest rate $\bar{r}$ and the premium for aggregate risk $\bar{\lambda}$ as given, and he does not internalize the impact of his investment decision on the equilibrium aggregate production $\sigma f(\bar{a})$. These behavioral assumptions lead to the following definition of "competitive" price conjecture: for each $a \in[0,1]$,

$$
\widetilde{E}^{1}(a):=\frac{\mathbb{E}\left[f^{1}(a)\right]}{1+\bar{r}}-\bar{\lambda} \operatorname{cov}\left(f^{1}(a), \sigma f(\bar{a})\right) .
$$

If the firm 1 maximizes the associated "competitive" market value function $a \mapsto$ $V^{1}(a):=\widetilde{E}^{1}(a)-a$, then the corresponding solution $\bar{a}$ is Pareto optimal. To see this, recall from the Second Welfare Theorem that, after appropriate transfers, the efficient allocation of consumption $\left(\bar{\xi}_{0}^{i}, \bar{\xi}_{1}^{i}\right)_{i \in I}$ can be implemented as the equilibrium of a pure exchange economy with a complete set of Arrow securities contingent on primitive states $\omega$. If we let $\bar{m}: \Omega \rightarrow \mathbb{R}_{+}$be the Arrow-Debreu stochastic discount factor (i.e., $\bar{m}(\omega) P(\omega)=\bar{p}(\omega)$, for all $\omega$ ), then we have

$$
\frac{v_{1}^{\prime}\left(\bar{\xi}_{1}^{i}\right)}{v_{0}^{\prime}\left(\bar{\xi}_{0}^{i}\right)}=\bar{m},
$$

for every investor $i$. This implies the following relation between the stochastic discount factor $\bar{\chi}$ from the bond-equity economy and the Arrow-Debreu factor $\bar{m}$ :

$$
\bar{\chi}(\sigma f(\bar{a}))=\bar{m} .
$$


As a consequence, we obtain

$$
\begin{aligned}
\widetilde{E}^{1}(a) & :=\frac{\mathbb{E}\left[f^{1}(a)\right]}{1+\bar{r}}-\bar{\lambda} \operatorname{cov}\left(f^{1}(a), \sigma f(\bar{a})\right) \\
& =\mathbb{E}\left[f^{1}(a)\right] \mathbb{E}[\bar{\chi}(\sigma f(\bar{a}))]-\operatorname{cov}\left(f^{1}(a), \bar{\chi}(\sigma f(\bar{a}))\right) \\
& =\mathbb{E}\left[f^{1}(a)\right] \mathbb{E}[\bar{m}]-\operatorname{cov}\left(f^{1}(a), \bar{m}\right) \\
& =\mathbb{E}\left[\bar{m} f^{1}(a)\right] \\
& =\Pi^{1}(a)+a .
\end{aligned}
$$

Therefore, an investment $\bar{a}$ maximizes $V^{1}(a)=\widetilde{E}^{1}(a)-a$ if, and only if, it maximizes $\Pi^{1}(a)$. From the First Welfare Theorem for Arrow-Debreu economies, such an investment level is a Pareto efficient productive decision.

Relating to our main framing The CAPM price conjecture defined in equation 6.2 could be obtained from our main framing by developing equation 4.2 as follows:

$$
\begin{aligned}
\widetilde{E}^{1}(a) & =\int_{Z} \widetilde{y}^{1}(a \mid z) \bar{\rho}(d z) \\
& =\int_{Y} \bar{\chi}(\sigma y) \widetilde{y}^{1}(a \mid \sigma y) Q(d y, \bar{a}) \\
& =\mathbb{E}\left[\bar{\chi}(\sigma f(\bar{a})) f^{1}(a)\right] \\
& =\frac{\mathbb{E}\left[f^{1}(a)\right]}{1+\bar{r}}-\bar{\lambda} \operatorname{cov}\left[f^{1}(a), \sigma f(\bar{a})\right],
\end{aligned}
$$

where $[1+\bar{r}]^{-1}:=\mathbb{E}[\bar{\chi}(\sigma f(\bar{a}))]$ is the equilibrium risk-free discount factor. This is the CAPM version of our concept of competitive price conjectures. When making out-of-equilibrium price conjectures, firms and agents take the risk-free discount factor $\bar{r}$ and the premium $\bar{\lambda}$ for aggregate risks as given and do not internalize the impact of the investment decision on aggregate output.

A similar decomposition for the market-value concept proposed by Magill and Quinzii (2009, 2010) leads to:

$$
\begin{aligned}
M\left(a^{k}\right)-a^{k} & :=\int_{Y} \bar{\chi}(\sigma y) y^{k} Q\left(d y,\left(a^{k}, \bar{a}^{-k}\right)\right) \\
& =\mathbb{E}\left[\bar{\chi}\left(\sigma f\left(a^{k}, a^{-k}\right)\right) f^{k}\left(a^{k}\right)\right] \\
& =\frac{\mathbb{E}\left[f^{k}\left(a^{k}\right)\right]}{1+r\left(a^{k}, \bar{a}^{-k}\right)}-\bar{\lambda} \operatorname{cov}\left(f^{k}\left(a^{k}\right), f^{k}\left(a^{k}\right)+\sum_{k^{\prime} \neq k} f^{k^{\prime}}\left(\bar{a}^{k^{\prime}}\right)\right)
\end{aligned}
$$

where $\left[1+r\left(a^{k}, \bar{a}^{-k}\right)\right]^{-1}:=\mathbb{E}\left[\bar{\chi}\left(\sigma f\left(a^{k}, \bar{a}^{-k}\right)\right]\right.$ is a modified risk-free discount factor, and $f^{k}\left(a^{k}\right)+\sum_{k^{\prime} \neq k} f^{k^{\prime}}\left(\bar{a}^{k^{\prime}}\right)$ is the out-of-equilibrium aggregate output. In this 
approach, firm $k$ is aware of its impact over the aggregate output and makes a conjecture about how its investment decision $a^{k}$ would affect the risk-free discount factor and the market risk premium.

Alternative strategic concepts for market value have been analyzed in the corporate finance literature. Important references includes Stiglitz (1972), Jensen and Long (1972), Fama (1972), Leland (1974), Merton and Subrahmanyam (1974), Greenberg, Marshall and Yawitz (1978), Baron (1979), James (1981), Greenberg, Marshall and Yawitz (1981), among others. These papers use the CAPM framing. They assume that firms take as given the equilibrium risk-free discount but incorporate (in different ways) the impact of alternative investments over the aggregate output.

\section{Conclusion}

There are two alternative traditions in economics to represent the outcome of risky enterprises. On one hand, the reference model in macroeconomics, finance, and general equilibrium uses the state-of-nature approach, which relies on random production functions that map investments and random primitive states of nature (with fixed objective probabilities) into realized outputs. On the other hand, the literature on contract theory relies on the probability approach in which production is modeled through transition functions mapping investments into probability measures over the set of possible outcomes.

As far as the description of production possibilities is concerned, the two approaches are equivalent. However, the two approaches differ on the financial contracts that are used to share risks and direct investments. By keeping states of nature hidden, the probability approach reminds us that writing contracts on the primitive states is not realistic. It is sometimes difficult to describe these states in a contract or to verify them ex-post for execution. This is why most financial contracts available in practice are usually written on observed production outcomes or profits (e.g., stocks and options). It is then natural to ask whether this market incompleteness - generated by the lack of state-contingent claims - matters for efficiency.

It is well-known that the ability to contract upon primitive states of nature is not essential for an efficient allocation of resources in exchange economies with endowment risks only. If agents can sell their endowed stocks and trade claims written on the aggregate output, then the equilibrium consumption is efficient and only varies with aggregate risks. The interesting question concerns the ability of financial markets to efficiently direct firms' investments. We show that the difficulty raised by the lack of state prices can be overcome if firms and agents competitively anticipate out-of-equilibrium scenarios. The corresponding market value conjecture is then consistent with an appropriate notion of competitive beliefs out of the equilibrium. It describes the way each firm assesses the impact of alternative out-of-equilibrium 
investments without anticipating the effect of this decision over the distribution of aggregate variables. As a result, we obtain the classic recipe that shareholder value maximization leads to Pareto efficiency even for the more realistic financial structure in which all contracts are written on firms' outcomes.

\section{A Appendix}

\section{A.1 Proof of Proposition 3.1}

Assume by way of contradiction that there is a feasible allocation $\left(\left(x_{0}, x_{1}\right), \bar{a}\right)$ that Pareto dominates $\left(\left(\bar{x}_{0}, \bar{x}_{1}\right), \bar{a}\right)$. Since the consumption market clearing condition (3.4) only involves aggregate output and agents are risk-averse, the allocation $\left(\left(x_{0}, \tilde{x}_{1}\right), \bar{a}\right)$ also Pareto dominates $\left(\left(\bar{x}_{0}, \bar{x}_{1}\right), \bar{a}\right)$, where

$$
\tilde{x}_{1}^{i}(y):=c_{1}^{i}(\sigma y) \quad \text { with } \quad c_{1}^{i}(z):=\int_{Y} x_{1}^{i}(y) Q(d y, \bar{a} \mid z)
$$

and $Q(B, \bar{a} \mid z):=P(\{f(\bar{a}) \in B\} \mid \sigma f(\bar{a})=z)$ is the probability that firms' production profile belongs to a Borel set $B \subseteq Y$, under the investment vector $\bar{a}$ and conditional on the aggregate production being $z$. Since the function $\tilde{x}_{1}^{i}$ only varies with the aggregate output $\sigma y$, this consumption level is implemented by the portfolio $\left(\theta^{i}, \eta^{i}\right):=\left(c_{1}^{i}, 0\right)$, in the sense that $\left(\tilde{x}_{1}^{i}, \theta^{i}, \eta^{i}\right)$ satisfies equation 3.2 . Since the plan $\left(\bar{x}_{0}^{i}, \bar{x}_{1}^{i}, \bar{\eta}^{i}, \bar{\theta}^{i}\right)$ solves agent $i$ 's optimization problem given $(\bar{E}, \bar{\rho}, \bar{a})$, we must have

$$
x_{0}^{i}+\int_{Z} c_{1}^{i}(z) \bar{\rho}(d z)+\bar{E} \cdot 0 \geqslant e_{0}^{i}+(\bar{E}-\bar{a}) \cdot \delta^{i},
$$

for every agent $i$, with a strict inequality for at least one $i$. By non-arbitrage, we know that

$$
\int_{Z} z \bar{\rho}(d z)=\bar{E} \cdot \mathbf{1}
$$

Therefore, by adding inequality A.1 over $i$, we find

$$
\sum_{i \in I}\left(x_{0}^{i}-e_{0}^{i}\right)+\bar{a} \cdot \mathbf{1}>0,
$$

which contradicts the date-0 consumption market clearing condition 3.3 .

\section{A.2 Proof of Proposition 4.1}

From AD to FE Let us take an Arrow-Debreu equilibrium $\left(\bar{p},\left(\bar{\xi}_{0}, \bar{\xi}_{1}\right), \bar{a}\right)$ and construct a financial equilibrium $\left(\bar{E}, \bar{\rho},\left(\bar{x}_{0}, \bar{x}_{1}, \bar{\eta}, \bar{\theta}\right)\right)$ associated with the investment vector $\bar{a}$. We define the equity and output-contingent prices as

$$
\bar{E}:=\int_{\Omega} f(\omega, \bar{a}) \bar{p}(d \omega) \quad \text { and } \quad \bar{\rho}(B):=\int_{\Omega} \mathbf{1}_{B}(\sigma f(\omega, \bar{a})) \bar{p}(d \omega)
$$


for any Borel set $B \subseteq Z$. It follows from strict concavity of $u_{1}$ that $\bar{\xi}_{1}(\omega)$ is constant across states $\omega$ associated with the same equilibrium aggregate output $\sigma f(\omega, \bar{a})$. This is to say that, for each agent $i$, there exists a Borel-measurable function $\bar{c}_{1}^{i}: Z \rightarrow \mathbb{R}_{+}$ satisfying $\bar{c}_{1}^{i}(z)=\bar{\xi}_{1}^{i}(\omega)$, for every $\omega$ such that $\sigma f(\omega, \bar{a})=z$. We pose

$$
\left(\bar{x}_{0}, \bar{x}_{1}(y)\right):=\left(\bar{\xi}_{0}, \bar{c}_{1}(\sigma y)\right), \quad \text { for every } y .
$$

The individual consumption plan $\left(\bar{\xi}_{0}^{i}, \bar{\xi}_{1}^{i}\right)$ must satisfy the Arrow-Debreu budget constraint

$$
\bar{\xi}_{0}^{i}+\int_{\Omega} \bar{\xi}_{1}^{i}(\omega) \bar{p}(d \omega) \leqslant e_{0}^{i}+\Pi(\bar{a}) \cdot \delta^{i} .
$$

Given the equity prices defined before, we have

$$
\Pi^{k}\left(\bar{a}^{k}\right)=\bar{E}^{k}-\bar{a}^{k}, \quad \text { for every } k .
$$

This allows us to rewrite the previous inequality as

$$
\bar{x}_{0}^{i}+\int_{Z} \bar{c}_{1}^{i}(z) \bar{\rho}(d z) \leqslant e_{0}^{i}+(\bar{E}-\bar{a}) \cdot \delta^{i} .
$$

Therefore, by taking $\bar{\eta}^{i}:=(1 / I) \mathbf{1}$ and $\bar{\theta}^{i}(z):=\bar{c}_{1}^{i}(z)-z / I$, we have that $\left(\bar{x}_{0}^{i}, \bar{x}_{1}^{i}, \bar{\eta}^{i}, \bar{\theta}^{i}\right)$ satisfies the budget constraints 3.1$)$ and $(3.2)$ at the equilibrium financial prices $(\bar{E}, \bar{\rho})$.

The consumption plans $\left(\bar{x}_{0}^{i}, \bar{x}_{1}^{i}\right)$ are optimal among all plans that can be financed by equity holdings and output-contingent contracts. To see this, let $\left(x_{0}^{i}, x_{1}^{i}, \eta^{i}, \theta^{i}\right)$ be an alternative plan satisfying the budget constraints (3.1) and (3.2) at the equilibrium prices $(\bar{E}, \bar{\rho})$. We construct the state-contingent plan $\xi_{0}^{i}:=x_{0}^{i}$ and $\xi_{1}^{i}(\omega):=$ $x_{1}^{i}(f(\omega, \bar{a}))$ and notice from equation 3.2 that

$$
\begin{aligned}
\int_{\Omega} x_{1}^{i}(f(\omega, \bar{a})) \bar{p}(d \omega) & =\int_{\Omega} \theta^{i}(\sigma f(\omega, \bar{a})) \bar{p}(d \omega)+\eta^{i} \cdot \int_{\Omega} f(\omega, \bar{a}) \bar{p}(d \omega) \\
& =\int_{Z} \theta^{i}(z) \bar{\rho}(d z)+\eta^{i} \cdot \bar{E} .
\end{aligned}
$$

By replacing this relation into equation (3.1) and using equation $(\mathrm{A.2})$, we deduce that the consumption plan $\left(\xi_{0}^{i}, \xi_{1}^{i}\right)$ satisfies the present-value budget constraint (4.7). Therefore, by optimality of $\left(\bar{\xi}_{0}^{i}, \bar{\xi}_{1}^{i}\right)$, we have

$$
\begin{aligned}
u_{0}\left(x_{0}^{i}\right)+\int_{Y} u_{1}\left(x_{1}^{i}(y)\right) Q(d y, \bar{a}) & =u_{0}\left(\xi_{0}^{i}\right)+\int_{\Omega} u_{1}\left(\xi_{1}^{i}(\omega)\right) P(d \omega) \\
& \leqslant u_{0}\left(\bar{\xi}_{0}^{i}\right)+\int_{\Omega} u_{1}\left(\bar{\xi}_{1}^{i}(\omega)\right) P(d \omega) \\
& =u_{0}\left(\bar{x}_{0}^{i}\right)+\int_{Y} u_{1}\left(\bar{x}_{1}^{i}(y)\right) Q(d y, \bar{a}) .
\end{aligned}
$$

Feasibility of the allocation $\left(\left(\bar{\xi}_{0}, \bar{\xi}_{1}\right), \bar{a}\right)$ as defined by equations 4.5$)$ and 4.6$)$ implies feasibility of the allocation $\left(\left(\bar{x}_{0}, \bar{x}_{1}\right), \bar{a}\right)$ as defined by equations (3.3) and (3.4). 
Since the portfolio allocation $(\bar{\eta}, \bar{\theta})$ satisfies the market clearing condition 3.5 , we can then deduce that $\left(\bar{E}, \bar{\rho},\left(\bar{x}_{0}, \bar{x}_{1}, \bar{\eta}, \bar{\theta}\right)\right)$ is a financial equilibrium associated with $\bar{a}$.

To conclude, we recall that $\bar{a}^{k}$ maximizes $\Pi^{k}$ and show that the objective function $V^{k}$ is identical to $\Pi^{k}$ given the equilibrium prices derived before. Indeed, standard first-order conditions applied to each agent's problem in the Arrow-Debreu equilibrium imply that $\bar{p}(d \omega)=\bar{\chi}(\sigma f(\omega, \bar{a})) P(d \omega)$, where $\bar{\chi}(z):=u_{1}^{\prime}\left(\bar{c}_{1}^{i}(z)\right) / u_{0}^{\prime}\left(\bar{\xi}_{0}^{i}\right)$ for every $z$. We have $\bar{\rho}(d z)=\bar{\chi}(z) \mu(d z, \bar{a})$, by construction, and then

$$
\begin{aligned}
V^{k}\left(a^{k}\right) & =\int_{Z} \widetilde{y}^{k}\left(a^{k} \mid z\right) \bar{\rho}(d z)-a^{k} \\
& =\int_{Z} \bar{\chi}(z) \widetilde{y}^{k}\left(a^{k} \mid z\right) \mu(d z, \bar{a})-a^{k} \\
& =\int_{Z} \bar{\chi}(z)\left[\int_{Y^{k}} y^{k} Q\left(d y^{k}, a^{k} \mid z\right)\right] \mu(d z, \bar{a})-a^{k} \\
& =\int_{Z} \bar{\chi}(z)\left[\int_{\Omega} f^{k}\left(\omega, a^{k}\right) P(d \omega \mid \sigma f(\bar{a})=z)\right] \mu(d z, \bar{a})-a^{k} \\
& =\int_{\Omega} \bar{\chi}(\sigma f(\omega, \bar{a})) f^{k}\left(\omega, a^{k}\right) P(d \omega)-a^{k} \\
& =\Pi^{k}\left(a^{k}\right) .
\end{aligned}
$$

From FE to AD We now take a financial equilibrium $\left(\bar{E}, \bar{\rho},\left(\bar{x}_{0}, \bar{x}_{1}, \bar{\eta}, \bar{\theta}\right)\right)$ associated with investments $\bar{a}$ such that $\bar{a}^{k}$ that maximizes $V^{k}$, for every $k$, and construct an Arrow-Debreu equilibrium $\left(\bar{p},\left(\bar{\xi}_{0}, \bar{\xi}_{1}\right), \bar{a}\right)$. Recall from the proof of Proposition 3.1 that there is a Borel-measurable function $\bar{\chi}: Z \rightarrow \mathbb{R}_{+}$representing the stochastic discount factor in the sense that $\bar{\chi}(\sigma y)=u_{1}^{\prime}\left(\bar{x}_{1}^{i}(y)\right) / u_{0}^{\prime}\left(\bar{x}_{0}^{i}\right)$ for every $y$ and $i$. We then pose

$$
\bar{p}(d \omega):=\bar{\chi}(\sigma f(\omega, \bar{a})) P(d \omega), \quad \bar{\xi}_{0}^{i}:=\bar{x}_{0}^{i}, \quad \text { and } \quad \bar{\xi}_{1}^{i}(\omega):=\bar{x}_{1}^{i}(f(\omega, \bar{a})) .
$$

The allocation $\left(\left(\bar{\xi}_{0}, \bar{\xi}_{1}\right), \bar{a}\right)$ satisfies the market clearing conditions 4.5 and 4.6). As for budget feasibility, we notice that, for each $i$, there is a Borel-measurable function $\bar{c}_{1}^{i}: Z \rightarrow \mathbb{R}_{+}$satisfying $\bar{c}_{1}^{i}(z)=\bar{x}_{1}^{i}(\sigma y)$, for all $y{ }^{21}$ The budget constraints (3.1) and $(3.2)$ can be consolidated as

$$
\bar{x}_{0}^{i}+\int_{Z} \bar{c}_{1}^{i}(z) \bar{\chi}(z) \mu(d z, \bar{a}) \leqslant e_{0}^{i}+(\bar{E}-\bar{a}) \cdot \delta^{i} .
$$

The definitions of $\bar{E}$ and $\bar{\rho}$ imply

$$
\bar{\xi}_{0}^{i}+\int_{\Omega} \bar{\xi}_{1}^{i}(\omega) \bar{p}(d \omega) \leqslant e_{0}^{i}+\Pi(\bar{a}) \cdot \delta^{i}
$$

and, then, the plan $\left(\bar{\xi}_{0}^{i}, \bar{\xi}_{1}^{i}\right)$ satisfies the present-value budget constraint (4.7).

\footnotetext{
${ }^{21}$ See the proof of Proposition 3.1
} 
To prove that $\left(\bar{\xi}_{0}^{i}, \bar{\xi}_{1}^{i}\right)$ is individually optimal, we fix an arbitrary consumption plan $\left(\xi_{0}^{i}, \xi_{1}^{i}\right)$ satisfying the present-value budget constraint

$$
\xi_{0}^{i}+\int_{\Omega} \xi_{1}^{i}(\omega) \bar{p}(d \omega) \leqslant e_{0}^{i}+\Pi(\bar{a}) \cdot \delta^{i}
$$

By posing

$$
c_{1}^{i}(z):=\int_{\Omega} \xi_{1}^{i}(\omega) P(d \omega \mid \sigma f(\bar{a})=z),
$$

we get from the definitions of $\bar{E}$ and $\bar{\rho}$ that A.3 writes as follows

$$
\xi_{0}^{i}+\int_{Z} c_{1}^{i}(z) \bar{\rho}(d z) \leqslant e_{0}^{i}+(\bar{E}-\bar{a}) \cdot \delta^{i} .
$$

By fixing $x_{0}^{i}:=\xi_{0}^{i}, x_{1}^{i}\left(y_{1}\right):=c_{1}^{i}\left(\sigma y_{1}\right), \theta^{i}(z):=c^{i}(z)$ and $\eta^{i}:=0$, we have that the plan $\left(x_{0}^{i}, x_{1}^{i}, \theta^{i}, \eta^{i}\right)$ must satisfy the budget restrictions (3.1) and (3.2). The optimality of $\left(\bar{x}_{0}^{i}, \bar{x}_{1}^{i}, \bar{\theta}^{i}, \bar{\eta}^{i}\right)$ then implies that

$$
\begin{aligned}
u_{0}\left(\xi_{0}^{i}\right)+\int_{\Omega} u_{1}\left(\xi_{1}^{i}(\omega)\right) P(d \omega) & =u_{0}\left(x_{0}^{i}\right)+\int_{Y} u_{1}\left(x_{1}^{i}(y)\right) Q(d y, \bar{a}) \\
& \leqslant u_{0}\left(\bar{x}_{0}^{i}\right)+\int_{Y} u_{1}\left(\bar{x}_{1}^{i}(y)\right) Q(d y, \bar{a}) \\
& =u_{0}\left(\bar{\xi}_{0}^{i}\right)+\int_{\Omega} u_{1}^{i}\left(\bar{\xi}_{1}^{i}(\omega)\right) P(d \omega) .
\end{aligned}
$$

Finally, since $\bar{a}^{k}$ maximizes $V^{k}$ and $V^{k}=\Pi^{k}$, the Arrow-Debreu profit maximization condition is also satisfied.

\section{A.3 Technology example}

We consider the following technology to illustrate that completeness with respect to aggregate output does not yield (even generically) complete markets with respect to the states of nature. There is a single firm, and the primitive states $\omega=\left(\omega_{1}, \omega_{2}\right)$ lie in $\Omega:=[1, \infty) \times[0,1)$. The production function (see figure 1 maps investment $a \in[0,1]$ to output $f(\omega, a) \in[0,1]$ and displays piece-wise constant returns to scale as follows:

$$
f(\omega, a):=\left\{\begin{array}{lll}
\omega_{1} a & \text { if } & a \in\left[0, a_{\omega}\right] \\
\omega_{2} a+\left(\omega_{1}-\omega_{2}\right) a_{\omega} & \text { if } & a \in\left[a_{\omega}, 1\right]
\end{array}\right.
$$

where the threshold is defined by $a_{\omega}:=\left(1-\omega_{2}\right) /\left(\omega_{1}-\omega_{2}\right)$. In words, our firm earns a high marginal productivity $\omega_{1} \in[1, \infty)$ for low investment levels and a low marginal return $\omega_{2} \in[0,1]$ for high investment levels.

[PLACE FIGURE 1 HERE] 
For each given equilibrium investment $\bar{a} \in[0,1]$ and production $z>\bar{a}$, there are infinitely many possible shocks $\omega \in \Omega$ that generate $f(\omega, \bar{a})=z$. To see this, take $z>\bar{a}, \bar{\omega}_{1}:=z / \bar{a}$, and $\bar{\omega}_{2}:=(1-z) /(1-\bar{a})$. We obtain $f(\omega, \bar{a})=z$ for any $\omega$ such that: (a) $\omega_{1}=\bar{\omega}_{1}$ and $\omega_{2} \leqslant \bar{\omega}_{2}$, or (b) $\omega_{1} \geqslant \bar{\omega}_{1}$ and $\omega_{2}=\bar{\omega}_{2}$. Figure 2 illustrates these cases. We conclude that observing the output $z$ is not sufficient to pin down exactly the underlying productive shock.

[PLACE FIGURE 2 HERE] 


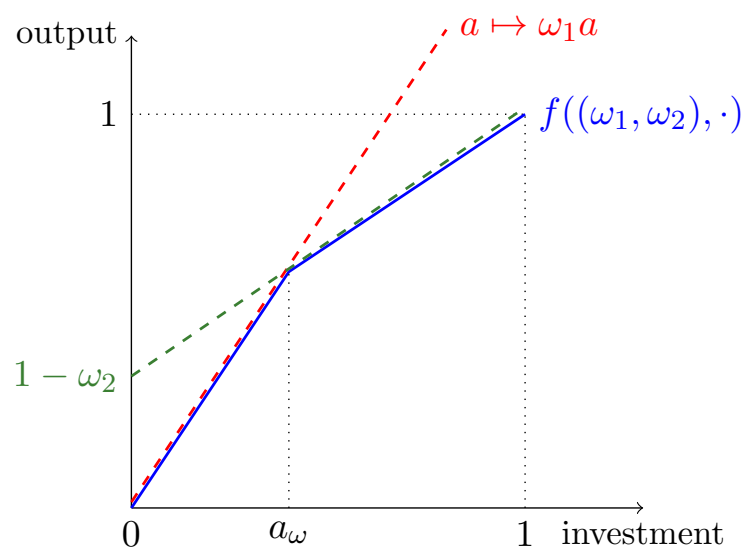

Figure 1: The production function $f\left(\left(\omega_{1}, \omega_{2}\right), \cdot\right)$
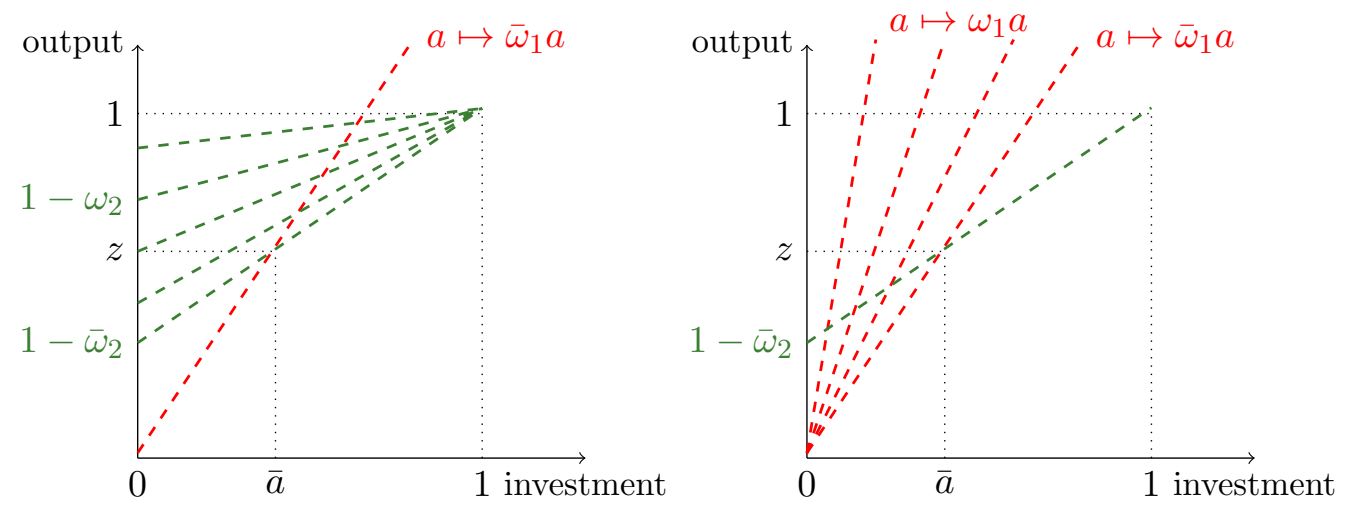

(a) $\omega_{1}=\bar{\omega}_{1}$ and $\omega_{2} \leqslant \bar{\omega}_{2}$

(b) $\omega_{1} \geqslant \bar{\omega}_{1}$ and $\omega_{2}=\bar{\omega}_{2}$

Figure 2: Production functions consistent with $z=f(\omega, \bar{a})$ 


\section{References}

Arrow, K. J., "Le role des valeurs boursières pour la répartition la meilleure des risques," Econométrie, Colloques Internationaux du Centre National de la Recherche Scientifique 40 (1953), 41-47.

BARon, D. P., "Investment policy, optimality, and the mean-variance model," Journal of Finance 34 (1979), pp. 207-232.

BEWLey, T. F., "Existence of equilibria in economies with infinitely many commodities," Journal of Economic Theory 4 (1972), 514-540.

Bisin, A., P. Gottardi and G. Ruta, "Equilibrium corporate finance and intermediation," NBER Working Paper No. 20345, 2014.

Braido, L. H. B. And V. F. Martins-DA-Rocha, "Supplement to 'Output contingent securities and efficient investment by firms'," Available at SSRN: https://ssrn.com/abstract=2954554, 2017.

Debreu, G., Theory of Value: An Axiomatic Analysis of Economic Equilibrium (New York: John Wiley \& Sons Inc., 1959).

Drèze, J. H., "Investment under private ownership: Optimality, equilibrium and stability," in J. H. Drèze, ed., Allocation Under Uncertainty: Equilibrium and Optimality (Macmillan, New York, 1974), 129-165.

EKERN, S., "On the theory of the firm in an economy with incomplete markets: an addendum," Bell Journal of Economics and Management Science 6 (1975), 388-393.

Ekern, S. AND R. WiLSOn, "On the theory of the firm in an economy with incomplete markets," Bell Journal of Economics and Management Science 5 (1974), 171-180.

FAMA, E. F., "Perfect competition and optimal production decisions under uncertainty," Bell Journal of Economics and Management Science 3 (1972), 509-530.

Geanakoplos, J. and H. Polemarchakis, "Existence, regularity and constrained suboptimality of competitive allocations when the asset market is incomplete," in W. Heller and D. Starrett, eds., Uncertainty, Information and Communication: Essays in Honor of K.J. Arrow, vol. III (Cambridge: Cambridge University Press, 1986), 65-96.

Greenberg, E., W. J. Marshall and J. B. Yawitz, "The technology of risk and return," American Economic Review 68 (1978), 241-251. 
, "The technology of risk and return: Reply," American Economic Review 71 (1981), 491-492.

Grossman, S. J. And O. D. Hart, "A theory of competitive equilibrium in stock market economies," Econometrica 47 (1979), 293-329.

HART, O., "On shareholder unanimity in large stock market economies," Econometrica 47 (1979), 1057-1083.

HaYeK, F. A., "The use of knowledge in society," American Economic Review 35 (1945), 519-530.

James, C., "The technology of risk and return: Comment," American Economic Review 71 (1981), 485-490.

Jensen, M. C. AND J. B. J. LONG, "Corporate investment under uncertainty and pareto optimality in the capital markets," Bell Journal of Economics and Management Science 3 (1972), 151-174.

Leland, H. E., "Production theory and the stock market," Bell Journal of Economics and Management Science 5 (1974), 125-144.

Magill, M. And M. QuinziI, The Theory of Incomplete Markets (Boston: MIT Press, 1996).

_- "The probability approach to general equilibrium with production," Economic Theory 39 (2009), 1-41.

— , "A comoment criterion for the choice of risky investment by firms," International Economic Review 51 (2010), 723-744.

Makowski, L., "Competitive stock markets," Review of Economic Studies 50 (1983), 305-330.

Merton, R. C. and M. G. Subrahmanyam, "The optimality of a competitive stock market," Bell Journal of Economics and Management Science 5 (1974), 145-170.

Ross, S. A., "Options and efficiency," The Quarterly Journal of Economics 90 (1976), 75-89.

Stiglitz, J. E., "On the optimality of the stock market allocation of investment," Quarterly Journal of Economics 86 (1972), 25-60. 